\title{
Performance assessment of the FAO AquaCrop model for soil water, soil evaporation, biomass and yield of soybeans in North China Plain
}

\author{
Paredes, P. ${ }^{1 *}$, Wei, Z. ${ }^{2,3^{*}}$, Liu, Y. ${ }^{2,3}$, Xu, D. ${ }^{2,3}$, Xin, Y. ${ }^{2}$, Zhang, B. ${ }^{2}$, Pereira, L.S. ${ }^{1 \text { (a) }}$ \\ 1. CEER-Biosystems Engineering, Institute of Agronomy, University of Lisbon, Tapada da Ajuda, 1349-017 \\ Lisbon, Portugal; \\ 2. State Key Laboratory of Simulation and Regulation of Water Cycle in River Basin, China Institute of Water \\ Resources and Hydropower Research, China; \\ 3. National Center of Efficient Irrigation Engineering and Technology Research, Beijing 100048, China \\ * These authors contributed equally to the present study \\ ${ }^{(a)}$ Corresponding author lspereira@isa.ulisboa.pt
}

\section{Abstract:}

Four years of soybean experimental data observed at Daxing, North China Plain, were used to assess the ability of the AquaCrop model to predict soybean final biomass and yield. The model was parameterized and calibrated using field data on leaf area index (LAI), available soil water, soil evaporation, biomass and final yield data. The model was assessed using calibrated and default parameters. Data on LAI was used to derive the fraction of ground cover and to calibrate the green canopy cover (CC) curve. An accurate calibration of the CC curve was performed, with low root mean square errors (RMSE $<7.3 \%$ ). Results relative to soil water balance simulations show a high variability of the predictions, thus a bias of the estimation, with $\mathrm{R}^{2}$ ranging $0.22-0.86$ and low Nash-Sutcliffe efficiency EF, ranging between -0.47 and 0.82 . The estimation errors were relatively high, with RMSE not exceeding $22.9 \mathrm{~mm}$. AquaCrop was compared with the soil water balance model SIMDualKc, that has shown better performance with $\mathrm{R}^{2} \geq 0.83$, EF generally greater than 0.75 and RMSE smaller than $12.5 \mathrm{~mm}$. The soil evaporation $\left(\mathrm{E}_{\mathrm{s}}\right)$ simulations were compared with the observations performed using microlysimeters; results for Aquacrop have shown a clear trend for underestimation of $E_{s}$, with "goodness-of-fit" results worse than for SIMDualKc (Wei et al., 2015). In general, AquaCrop has shown serious limitations to estimate crop transpiration or soil 
evaporation, which is likely due to abandoning the FAO dual $\mathrm{K}_{\mathrm{c}}$ approach. However, the model performed well relative to biomass and yield predictions, with a yield RMSE of $302 \mathrm{~kg}$ $\mathrm{ha}^{-1}$. Overall, results show the adequacy of AquaCrop for estimating soybean biomass and yield when the model is appropriately parameterized. However, AquaCrop is not appropriate to support irrigation scheduling.

Keywords: Crop coefficients curve, Dual crop coefficient approach, Partitioning crop evapotranspiration, Plant transpiration, Soil water balance, SIMDualKc model

\section{Introduction}

Soybeans are a main summer crop in North China Plain, where they are cropped during the rainy season, thus only requiring supplemental irrigation to fulfil the crop water requirement. The prediction of the soybean yield and of the yield response to water is mandatory for developing strategies for irrigation management and to support related farmers' decisionmaking under limited water availability conditions.

To assess the impacts of different irrigation scheduling strategies on yield various modelling approaches may be used such as coupling a soil water balance model with water yield functions describing the relationships between crop evapotranspiration or crop transpiration with yield. A successful approach applied to soybeans is described by Wei et al. (2015) that adopted the SIMDualKc soil water balance model (Rosa et al., 2012) coupled with the Stewart's water-yield model (Stewart et al., 1977). The SIMDualKc model applies the FAO dual crop coefficient approach for computing and partitioning the daily crop evapotranspiration $\left(\mathrm{ET}_{\mathrm{c}}, \mathrm{mm}\right)$ into crop transpiration $\left(\mathrm{T}_{\mathrm{c}}, \mathrm{mm}\right)$ and soil evaporation $\left(\mathrm{E}_{\mathrm{s}}, \mathrm{mm}\right)$. SIMDualKc performs a daily soil water balance for the entire root zone and a daily water balance of the soil evaporation layer adopting the two stages Ritchie's evaporation approach (Ritchie, 1972; Allen et al., 1998; Allen and Pereira, 2009). Deep percolation (DP, mm) and capillary rise $(\mathrm{CR}, \mathrm{mm})$ are computed using the parametric equations proposed by Liu et al. 
(2006), and runoff (RO) is estimated using the curve number (CN) approach (Allen et al., 2007). SIMDualKc allows computing the daily $E_{c}$ and $T_{c}$ deficits $\left(E T_{d}\right.$ and $\left.T_{d}\right)$ defined respectively as the difference between the standard $\mathrm{ET}_{\mathrm{c}}$ and the actual $\mathrm{ET}\left(\mathrm{ET}_{\mathrm{c} \text { act }}\right)$ and as the difference between $T_{c}$ and actual transpiration $\left(T_{a}\right)$. Those values may be used with the Stewart's water-yield model (Stewart et al., 1977), thus adopting a simple, linear crop-water production function that relates seasonal $\mathrm{ET}_{\mathrm{d}}$ or $\mathrm{T}_{\mathrm{d}}$ with the relative yield loss $(\mathrm{RYL})$ through an appropriate water-yield factor, $\mathrm{K}_{\mathrm{y}}$, as reported by Paredes et al. (2014a) for maize.

A more complex modelling approach is used in the FAO crop yield model AquaCrop (Raes et al., 2012; Steduto et al., 2012), that simulates crop biomass and yield in response to water and other abiotic stresses (temperature, fertilization, salinity, $\mathrm{CO}_{2}$ ). AquaCrop uses an empirical approach to estimate $T_{c}$ and $E_{s}$ depending upon the canopy cover curve, which is different from the FAO dual $\mathrm{K}_{\mathrm{c}}$ approach described in FAO56 (Allen et al., 1998) and bases upon a $\mathrm{K}_{\mathrm{c}}$ curve that does not relate with the common FAO $\mathrm{K}_{\mathrm{c}}$ curve adopted in FAO24 and FAO 56 (Doorenbos and Pruitt, 1977; Allen et al., 1998). AquaCrop performs a daily soil water balance and estimates RO using also the CN method. Differently from SIMDualKc, it uses a semi-empiric DP estimation procedure that requires the knowledge of the saturated hydraulic conductivity, $\mathrm{K}_{\text {sat }}$, throughout the soil profile (Raes et al., 2006).

The AquaCrop model was already applied to several annual field crops but only a few applications analysed the model behaviour relative to the soil water and evapotranspiration, e.g., Farahani et al. (2009) for cotton, Katerji et al. (2013) for tomato, and Paredes et al. (2014b) for maize. However, assessments of ET partitioning in AquaCrop are limited (Pereira et al., 2015b) and there are no assessments of the model's ability to predict soil evaporation.

Considering the above discussions on the possible appropriateness and limitations of the AquaCrop model, as well as the previous results obtained when using the SIMDualKc and Stewart's modelling approaches described by Wei et al. (2015), the objectives of the present 
80

study are: 1) assessing the performance of AquaCrop for soybean yield estimation when using calibrated and default parameters; 2) to test the AquaCrop ability to partitioning crop ET in comparison with the FAO dual Kc approach; 3) to assess the ability of AquaCrop to simulate soil evaporation comparing with observations performed with microlysimeters along four soybean seasons; and 4) to compare the AquaCrop approaches used for soil water balance and soil evaporation estimation with the ones used by the soil water balance SIMDualKc. The same data used by Wei et al. (2015) are used in this study.

\section{Material and methods}

\subsection{Experimental site characterisation and observations}

Soybean (Glycine max L.) experiments were performed at the Irrigation Experiment Station of the China Institute of Water Resources and Hydropower Research (IWHR) located at Daxing ( $39^{\circ} 37^{\prime} \mathrm{N}, 116^{\circ} 26^{\prime} \mathrm{E}$, and $40.1 \mathrm{~m}$ altitude). The soybean variety Zhonghuang No. 13 was sown using conventional tillage with a plant density of 15 plants $\mathrm{m}^{-2}$ and an inter-row spacing of $0.4 \mathrm{~m}$. This variety is a high-yielding semi-determinate cultivar that belongs to the maturity group II and takes an average of 96 days to reach full maturity (Wang et al., 2013). The experiments were performed from 2008 to 2011, with sowing by mid-June and harvesting by early October. Further information is provided by Wei et al. (2015).

The climate in the experimental site is sub-humid of monsoon type, with cold and dry winter and hot and humid summer, which is classified as Dwa according to the Köppen classification (Kottek et al., 2006). Climatic data used in the study were collected from an automatic meteorological station installed inside the experimental station. Daily data used included precipitation, maximum and minimum air temperature, relative humidity, global and net radiation, and wind speed at $2 \mathrm{~m}$ height. The climatic data sets were checked for quality assessment as recommended by Allen et al. (1998). The reference ET (ETo $)$ was computed 
with the FAO Penman-Monteith method (Allen et al., 1998). Table 1 presents the climatic characterization of the four crop seasons for the period 2008 to 2011. Detailed information on weather data relative to the four years of observations is provided by Wei et al. (2015).

Climatic data (Table 1) suggest that differences among years were small except relative to precipitation, which was higher in 2009 and 2011.

The soils in the experimental field are silty soils formed by deposits of the loess formations. By 2007, four undisturbed soil samples of $250 \mathrm{~cm}^{3}$ for each soil layer to a depth of $1 \mathrm{~m}$ were collected in various plots to determine the soil water retention curve and the hydraulic conductivity curve in laboratory. The ku-pf apparatus (Umwelt-Geräte-Technik, Müncheberg, Germany) was used. Averaged values of basic soil hydraulic properties are presented in Table 2. The $\mathrm{K}_{\text {sat }}$ values are in the range of those proposed by Rawls et al. (1998) and Raes et al. (2012) for silt loam soils, however they higher than those formerly observed in the region (Pereira et al., 2003). Capillary rise from the groundwater was not considered because the average groundwater table was deep, near $18 \mathrm{~m}$, in all four years of observations. The irrigation schedules were set using two soil water thresholds, of $75 \%$ and $60 \%$ of $\theta_{\mathrm{FC}}$, respectively treatment $\mathrm{T} 1$ and $\mathrm{T} 2$. Thus, irrigation was performed whenever the soil water content reached those thresholds. Treatments were performed with three replications in plots of $30 \mathrm{~m}^{2}$ each. Since the crop develops during the monsoon rainy season, lower irrigation thresholds could not be selected. In 2009 and 2011, due to abundant rainfall, no distinction could be made between treatments thus, resulting in a total of six data sets.

Field observations included:

(a) The dates of each crop growth stage (Table 3).

(b) The leaf area index (LAI, $\mathrm{cm}^{2} \mathrm{~cm}^{-2}$ ), that was measured along the crop season at several locations using a ceptometer (AccuPAR LP-80, Decagon Devices) and a leaf area scanner (F915900 model, Cannon). 
(c) The root depth $\left(Z_{r}, m\right)$, observed in randomly distributed plants; by full soil cover, $\mathrm{Z}_{\mathrm{r}}$ reached $1.0 \mathrm{~m}$ depth, hence in agreement with data reported by Yan (2007).

(d) The soil water content, that was monitored with a previously calibrated TDR system (TRIME®-T3/IPH, IMKO GmbH). Measurements were performed at each $0.10 \mathrm{~m}$ until the maximum depth of $1.0 \mathrm{~m}$, with three replications, every 5 days. When precipitation or an irrigation event occurred, the soil water content was measured in the following day. For

135 simulation purposes, the soil water content was converted into available soil water, which is the depth of water stored in the soil above the wilting point (ASW, mm).

(e) Soil evaporation, that was measured using two microlysimeters in each plot; the and transpiration was reduced.

(f) The final crop biomass and yield, that were determined by harvesting plant samples in each plot, with a total of 3 samples per treatment. The samples were placed in refrigerated containers until they were weighed in the lab to obtain the fresh weight and, later, oven dried at $65 \pm 5^{\circ} \mathrm{C}$ to obtain the dry weight.

Further description of the experiments and further observed data, namely relative to root depths and irrigation schedules, are presented by Wei et al. (2015).

\subsection{Modelling approaches. ET partitioning and yield prediction}

148 The Aquacrop model (Steduto et al., 2012; Raes et al., 2012) is basically a crop yield 149 model that computes biomass and yield considering the actual transpiration $\left(\mathrm{T}_{\mathrm{a}}, \mathrm{mm}\right)$. It separately computes $\mathrm{T}_{\mathrm{a}}$ and $\mathrm{E}_{\mathrm{s}}$ using a daily time step. The daily actual crop ET $\left(\mathrm{ET}_{\mathrm{c} \text { act }}, \mathrm{mm}\right.$

$$
\mathrm{T}_{\mathrm{a}}=\mathrm{K}_{\mathrm{s}} \mathrm{CC}^{*} \mathrm{~K}_{\mathrm{c}, \operatorname{Tr} \mathrm{x}} \mathrm{ET}_{\mathrm{o}}
$$


and

$$
\mathrm{E}_{\mathrm{s}}=\mathrm{K}_{\mathrm{r}}\left(1-\mathrm{CC}^{*}\right) \mathrm{K}_{\mathrm{ex}} \mathrm{ET}_{\mathrm{o}}
$$

where $\mathrm{ET}_{\mathrm{o}}$ is reference evapotranspiration $\left(\mathrm{mm} \mathrm{day}^{-1}\right), \mathrm{K}_{\mathrm{c}, \operatorname{Tr} \mathrm{x}}$ is the maximum standard crop transpiration coefficient (non-dimensional), or maximum basal crop coefficient when $\mathrm{CC}=$ $100 \%$; $\mathrm{CC}^{*}$ is the actual green crop canopy cover (\%) adjusted for micro-advective effects; $\mathrm{K}_{\mathrm{s}}$ $(0-1)$ is the water stress coefficient; $K_{e x}$ is the soil evaporation coefficient for fully wet and non-shaded soil surface (non-dimensional); and $\mathrm{K}_{\mathrm{r}}(0-1)$ is the evaporation reduction coefficient (Raes et al., 2012). Thus, the computation of both ET components is mainly tied to the simulated crop canopy cover (internally adjusted for micro-advective effects), CC*. This is an approach very different from FAO56 (Allen et al., 1998), thus from the approach used with SIMDualKc (Rosa et al., 2012) despite this model estimates $\mathrm{K}_{\mathrm{cb}}$ with a density coefficient $K_{d}$ that is a function of the fraction of ground covered or shaded by the crop ( $f_{c}$, non-dimensional) and of the crop height (h, m) as described by Allen and Pereira (2009).

The soil evaporation coefficient is computed in AquaCrop using a deep modification of the Ritchie's two stages approach, including a skin layer modification (Raes et al., 2012). Stage I is determined by the available energy at the soil surface, thus not limited by the evaporable water available in the surface soil layer; $\mathrm{E}_{\mathrm{s}}$ is then at its potential rate and it is assumed that water evaporates from a thin soil surface layer with $0.04 \mathrm{~m}$ depth that directly contacts with the atmosphere (Raes et al., 2012). When water is evaporated from this thin surface layer, an upwards flux from the soil layer underneath occurs and evaporation is in stage II. At this stage, evaporation is limited by the soil water availability and the soil hydraulic properties determining the transfer of water from the underneath soil layer to the evaporative surface layer. The soil water content in the underneath soil layer progressively decreases resulting in a decrease of the evaporation rate with time. AquaCrop uses a mechanistic approach to describe the falling evaporation rate during Stage II which makes that $\mathrm{K}_{\mathrm{r}}$ is computed as a function of 
time and, among other factors, of the amount of water extracted by the crop roots from the

179 upper soil layer and of the decline of the unsaturated hydraulic conductivity with the decrease of the soil water content. An exponential equation is used to relate the evaporation reduction coefficient $\mathrm{K}_{\mathrm{r}}$ with the relative water content of the surface soil layer, which depends of a decline factor $\left(\mathrm{f}_{\mathrm{K}}\right)$ and of the relative water content of the soil layer $\left(\mathrm{W}_{\text {rel }}\right)$ through which water moves to the evaporative surface layer. The default value $f_{K}=4$ is provided in the model manual, as well as of the thickness of the surface layer $(0.15 \mathrm{~m}$ including the skin layer). However, according to Raes et al. (2012), when $\mathrm{W}_{\text {rel }}$ drops below a threshold of 0.4, the thickness is expanded to a depth set by default as $0.3 \mathrm{~m}$. The approach is reasonable but has not been proved in practice or mentioned in any model users' publication. There is no reference to the need for calibration of the required parameters or relative to their calibration by the users.

SIMDualKc, contrastingly, computes $\mathrm{K}_{\mathrm{e}}$ with the Ritchie's model and by performing a daily soil water balance of the evaporable layer (Allen et al., 2005; Rosa et al., 2012). In SIMDualKc, the evaporable layer is characterized by its thickness $\left(Z_{e}, m\right)$, that is assumed to vary 0.10 to $0.15 \mathrm{~m}$, the total evaporable water (TEW, $\mathrm{mm}$ ), which is the maximum depth of water that can be evaporated from that soil layer after it has been fully wetted, and the readily evaporable water (REW, mm), which is the depth of water that can be evaporated without water availability restrictions, i.e., during stage I of soil drying. Furthermore, the evaporation coefficient $\mathrm{K}_{\mathrm{e}}$ is maximum when the soil is wet but is limited by the energy available at the soil surface, thus its value cannot exceed the difference $\mathrm{K}_{\mathrm{c} \max }-\mathrm{K}_{\mathrm{cb}}$, between the maximum

199 daily $\mathrm{K}_{\mathrm{c}}$ and the basal crop coefficient at the same day. As the topsoil dries and less water is 200 available for evaporation, a reduction in $E_{s}$ occurs in proportion to the amount of water 201 remaining in the surface soil layer, which is used to define the evaporation reduction 
coefficient $\left(\mathrm{K}_{\mathrm{r}}\right.$, non-dimensional) as described by Allen et al. (1998; 2005). Due to adopting different approaches, $\mathrm{K}_{\mathrm{r}}$ is obviously different in both models.

According to Raes et al. (2012), the model estimates the CC evolution along time in three distinct phases: a) the first phase begins at the crop emergence and ends when half of the maximum $\mathrm{CC}\left(\mathrm{CC}_{\mathrm{x}}\right)$ is attained; b) the second phase follows the previous one until $\mathrm{CC}_{\mathrm{x}}$ is reached; and c) the third phase begins when senescence starts and ends at harvest. An exponential function of time is used in the $1^{\text {st }}$ and $2^{\text {nd }}$ phases, beginning with the canopy cover when $90 \%$ emergence has occurred $\left(\mathrm{CC}_{\mathrm{o}}\right)$ and using a growth rate defined by the canopy growth coefficient (CGC). The third and last phase refers to the decline of green canopy cover and its shape is defined by the canopy decline coefficient (CDC). Therefore, to parameterize the $\mathrm{CC}$ curves it is necessary to use the four referred parameters $\mathrm{CC}_{\mathrm{o}}, \mathrm{CC}_{\mathrm{x}}, \mathrm{CGC}$ and $\mathrm{CDC}$. In 213 contrast, instead of simulating CC, SIMDualKc adopts the observed $\mathrm{f}_{\mathrm{c}}$ fraction of soil cover 214 by vegetation as defined FAO56 (Allen et al., 1998). In addition to the referred adjustment of $215 K_{c b}$ values through a density coefficient, $f_{c}$ is also used to limit $K_{e}\left(K_{e} \leq f_{e w} K_{c \max }\right)$ where the 216 fraction of soil wetted and exposed to solar radiation ( $\mathrm{f}_{\mathrm{ew}}$, non-dimensional), from where soil 217 evaporation originates, is depending on $f_{c}$ (Allen et al., 1998; 2005). The approaches used in 218 AquaCrop and with the dual $\mathrm{K}_{\mathrm{c}}$ methodology used in SIMDualKc are therefore different.

219 AquaCrop estimates the above ground dry biomass $\left(\mathrm{B}, \mathrm{t} \mathrm{ha}^{-1}\right)$ by multiplying the water transpired by the crop along the season $\left(\mathrm{T}_{\mathrm{a}}\right)$ by the adjusted biomass (water) productivity $\left(\mathrm{BWP}^{*}, \mathrm{~g} \mathrm{~m}^{-2}\right.$ ). BWP* represents the above ground biomass produced per unit of land area considering both the cumulative transpiration, after adjustment for atmospheric $\mathrm{CO}_{2}$ concentration and $\mathrm{ET}_{\mathrm{o}}$ (Raes et al., 2012). The actual yield $\left(\mathrm{Y}_{\mathrm{a}}, \mathrm{t} \mathrm{ha}^{-1}\right)$ is predicted by the model using the reference harvest index $\left(\mathrm{HI}_{\mathrm{o}}, \%\right)$ and $\mathrm{B}$. The $\mathrm{HI}_{\mathrm{o}}$ is adjusted when water stress occurs by a factor integrating five water stress factors relative to the inhibition of leaf growth, 
biomass due to pre-anthesis stress, and pollination failure (Raes et al., 2012). Relative to yield

228 estimation differences between AquaCrop and the Stewart's model are enormous because the latter uses just an empirical relation between the relative yield loss and the season ET deficit while AquaCrop uses a deterministic approach as briefly described above.

Further descriptions of the AquaCrop model and auxiliary equations are provided by Raes et al. (2012).

233

234

235

236

237

238

239

\subsection{Model parameterization, calibration and validation}

The AquaCrop model uses a large number of parameters relative to crop characteristics and effects of crop management on the crop growth. Some of those parameters, named conservative parameters, are expected to change little with time, with management condition or with the location. They are identified, described and tabled by Raes et al. (2012). These tabled values were used to start the simulations and were adjusted using field observations. Because CC determines the partition of ET into crop transpiration and soil evaporation (Eqs. 1 and 2), the parameterization firstly focused on the $\mathrm{CC}$ curve, i.e., the parameters $\mathrm{CC}_{\mathrm{o}}, \mathrm{CC}_{\mathrm{x}}$, CGC and CDC. The CC measured values were derived from the observed leaf area index (LAI) and crop height using the approach proposed by Allen and Pereira (2009), previously used with SIMDualKc (Wei et al., 2015). CC $_{\mathrm{o}}$ was obtained from plant density after emergence, $\mathrm{CC}_{\mathrm{x}}$ was the maximum $\mathrm{CC}$ observed for no water stress conditions, and a trial and error procedure was used for CGC and CDC. The trial and error procedure was initiated using parameter values tabled by Raes et al. (2012) and ended when the simulated CC curve fitted the observed CC values as described by Paredes et al. (2014b) in a previous application to maize. Subsequently, a trial and error procedure focused on adjusting the $\mathrm{K}_{\mathrm{c}, \mathrm{Tr} \mathrm{x}}$ by comparing simulated and observed field data of available soil water. In this application, the initial value for $\mathrm{K}_{\mathrm{c}, \operatorname{Tr} \mathrm{x}}$ was 1.10 as proposed by Raes et al. (2012). The model was calibrated with the data 
of Treatment 1 in 2008 and was tested with the remaining data collected in the crop seasons of 2008 to 2011.

To simulate soil evaporation, a value for the readily evaporable water ( $\mathrm{REW}, \mathrm{mm}$ ), was obtained from soil textural and hydraulic properties of the soil as defined by Allen et al. (1998). To estimate runoff, the curve number $(\mathrm{CN})$ method is used by the model; the $\mathrm{CN}$ values were obtained from tabled values proposed by Allen et al. (2007) for soils with medium

257 258

texture whose previous crop was a cereal. REW and $\mathrm{CN}$ were not obtained through the trial and error procedure because they were available from the previous calibration of the model SIMDualKc (Wei et al., 2015).

The reference harvest index $\mathrm{HI}_{\mathrm{o}}$ was obtained from yield data observations performed in all seasons, without occurring water stress; it resulted the average value $\mathrm{HI}_{\mathrm{o}}=0.38$. The retained $\mathrm{HI}_{\mathrm{o}}$ value is within the range of $\mathrm{HI}_{\mathrm{o}}$ values, 0.30 to 0.43 , reported by Donatelli et al. (1997) and is only slightly lower than values reported by Cui and $\mathrm{Yu}(2005)$ with $\mathrm{HI}_{\mathrm{o}}=0.41$.

The BWP* was obtained using a trial and error procedure aimed at minimizing differences between predicted and observed above ground dry biomass. BWP ${ }^{*}$ was set at $17 \mathrm{~g} \mathrm{~m}^{-2}$, which is slightly higher than the tabled value proposed by Raes et al. (2012) for soybean [15 $\left.\mathrm{g} \mathrm{m}^{-2}\right]$, and the range of values proposed by Steduto et al. (2012) [12 to $16 \mathrm{~g} \mathrm{~m}^{-2}$; however it is within the range of values proposed by the same authors for $\mathrm{C} 3$ plants.

The "goodness-of-fit" relative to both the calibration and validation processes was assessed using a set of indicators described previously (Wei et al., 2015). A linear regression forced through the origin was performed to compare observed and simulated (predicted) values, $\mathrm{O}_{\mathrm{i}}$ and $\mathrm{P}_{\mathrm{i}}$, whose means are respectively $\bar{O}$ and $\bar{P}$; the regression coefficient (b) and the determination coefficient $\left(\mathrm{R}^{2}\right)$ were then assumed as main statistical indicators. To analyse the residual estimation errors a set of indicators were also used, mainly the root mean square error 
275 (RMSE) to express the variance of errors (Bowermann et al., 2005), and the average relative 276 error (ARE) to indicate the average size of the estimated errors. These indicators are computed from the pairs of observed and predicted values $\mathrm{O}_{\mathrm{i}}$ and $\mathrm{P}_{\mathrm{i}}(\mathrm{i}=1,2, \ldots, \mathrm{n})$ as

$$
\mathrm{RMSE}=\left[\frac{\sum_{\mathrm{i}=1}^{\mathrm{n}}\left(\mathrm{P}_{\mathrm{i}}-\mathrm{O}_{\mathrm{i}}\right)^{2}}{\mathrm{n}}\right]^{0.5}
$$

279 and

$$
\mathrm{ARE}=\frac{100}{\mathrm{n}} \sum_{\mathrm{i}=1}^{\mathrm{n}}\left|\frac{\mathrm{O}_{\mathrm{i}}-\mathrm{P}_{\mathrm{i}}}{\mathrm{O}_{\mathrm{i}}}\right|
$$

These indicators were calculated at each iteration of the trial and error procedure to support

finding the calibrated parameters that lead to minimize the estimation errors.

In addition, an indicator of the quality of modelling was used, the Nash and Sutcliffe (1970) modelling efficiency (EF, non-dimensional), that is a normalized statistic which corresponds to the ratio between the residual variance and the observations variance

$$
E F=1.0-\frac{\sum_{i=1}^{n}\left(O_{i}-P_{i}\right)^{2}}{\sum_{i=1}^{n}\left(O_{i}-\bar{O}\right)^{2}}
$$

The target value for EF is 1.0, while a null or negative value indicates that the mean of observations is as good or better predictor than the model.

\section{Results and discussion}

\subsection{AquaCrop model parameterization, calibration and validation}

As previously referred, model calibration was performed using data of 2008-T1 by 
294 the interdependence of the calibrated model parameters, the main focus was the accuracy of B and $295 Y_{a}$ predictions. The parameterization of the CC curve was first performed.

Table 4 presents the default value (Raes et al., 2012) of the main model parameters used to 297 initiate the model application, as well as the calibrated values of the previously referred parameters $\mathrm{CC}_{\mathrm{o}}, \mathrm{CC}_{\mathrm{x}}, \mathrm{CGC}, \mathrm{CDC}, \mathrm{K}_{\mathrm{c}, \mathrm{Tr} \mathrm{x}}, \mathrm{BWP}^{*}$, and $\mathrm{HI}_{\mathrm{o}}$.

As previously discussed considering Eqs. 1 and 2, an accurate parameterization of the CC 300 curve is of major importance for appropriate computation of $T_{a}$ and $E_{s}$ and, subsequently, 301 estimating biomass and yield. Specific CGC and CDC were obtained for each year (Table 4).

Differences among years relate with the observed differences in CGDD required by the crop to 303 reach the crop development and mid-season stages (Table 3). Selected results of the fitted and the default CC curves are presented in Fig. 1. Relative to the calibrated CC curves, results show that the model tends to over-estimate $\mathrm{CC}$ during the initial and crop development stages and to slight 306 under-estimate CC during the mid-season in 2008 and 2009 (e.g. Fig. 1a) but to over-estimate in 2010 and 2011 (e.g. Fig. 1b). This may relate with the fact that AquaCrop internally adjusted the calibrated $\mathrm{CC}_{\mathrm{x}}$ (Table 4) to $97.9 \%$ for both treatments in 2008 and 2011, to $90.8 \%$ in 2009 , to 93.9\% and $95.2 \%$ respectively for $\mathrm{T} 1$ and $\mathrm{T} 2$ in 2010. Raes et al. (2012) explains internal model 310 adjustments as due to stress, but it was not observed or computed by the model in the present 311 study. If default parameters $\left(\mathrm{CC}_{\mathrm{x}}, \mathrm{CGC}\right.$ and $\mathrm{CDC}$ in Table 4$)$ are used there is a clear trend for under-estimation of the observed $\mathrm{CC}$ values mainly during the initial, crop development and mid 313 stage periods.

314 The "goodness-of-fit" indicators relative to the CC curves when using default and calibrated 315 parameters are presented in Table 5. After accurate calibration of the $\mathrm{CC}$ curve parameters $316\left(\mathrm{CC}_{\mathrm{o}}, \mathrm{CC}_{\mathrm{x}}, \mathrm{CGC}\right.$ and $\left.\mathrm{CDC}\right)$ results do not show any clear trend to over or under-estimation, 317 with $\mathrm{b}$ ranging from 0.96 to 1.04 (Table 5). The determination coefficients are high $\left(\mathrm{R}^{2}>\right.$ 318 0.91), indicating that the $\mathrm{CC}$ model is able to explain the variance of observed CC values. EF 
values are also high $(\geq 0.91)$, showing that the variance of residuals was much smaller than

320 the measured data variance. Consequently, the estimation errors are low, with RMSE ranging 4.3 to $7.4 \%$ (of canopy cover) and ARE not exceeding $10.2 \%$. If default parameters $\left(\mathrm{CC}_{\mathrm{x}}\right.$, $\mathrm{CC}$ values, with $\mathrm{b}$ ranging 0.73 to 0.86 . Estimation errors are high, with ARE exceeding $26.7 \%$, thus definitely non negligible. The model efficiency values are low, including a negative value, -0.71 , in 2011 , thus when $b$ is the smallest and errors are the highest. The less good results obtained when using default parameters relate with the natural variability of crop these were generally small except for rainfall.

Results discussed above indicate that the use of default values may lead to large inaccuracies in the computations that use the CC curves. Therefore, there is a need for an appropriate revision of the $\mathrm{CC}$ default values by the model developers. Meanwhile, it is advisable that at least a couple of CC curves should be locally calibrated and related results used as default parameters.

\subsection{Simulation of the available soil water}

Selected results relative to comparing the observed and simulated ASW after appropriate model calibration are presented in Fig. 2. Also included the values simulated with the default parameters listed in Table 4. ASW were observed and simulated for the maximum root depth. The target upper limit of ASW is the the total available soil water (TAW, mm) that corresponds to the ASW stored at field capacity in the root zone, and the target lower limit for

340 ASW without water stress is the readily available water, RAW $=p$ TAW, where $p$ is the 341 depletion fraction for no stress (Allen et al., 1998). In this application, $\mathrm{p}$ was previously 
occurred. This is due to the fact that irrigation treatments $\mathrm{T} 1$ and $\mathrm{T} 2$ were designed for 345 depletion fractions smaller than $\mathrm{p}$.

346 Fig. 2 shows that the model tends to under-estimate ASW during most of the mid-season 347 and end season and to over-estimate ASW during crop development and part of the mid348 season. This behavior is particularly evident for 2010 and 2011 (Fig. 2c and d). Results 349 indicate a bias in the estimation of the ASW along the season. Bias in the soil water 350 simulation by AquaCrop were identified in studies relative to barley (Pereira et al., 2015b), 351 cotton (Farahani et al., 2009) and maize (Paredes et al., 2014b). The analysis by Pereira et al. (2015b) suggests that the referred biased estimation of ASW is likely due to AquaCrop abandoning the FAO $\mathrm{K}_{\mathrm{c}}$ and $\mathrm{K}_{\mathrm{cb}}$ curve, changing the procedures to compute $\mathrm{K}_{\mathrm{e}}$, and thus abandoning the FAO dual $\mathrm{K}_{\mathrm{c}}$ approach to make $\mathrm{T}_{\mathrm{a}}$ and $\mathrm{E}_{\mathrm{s}}$ to depend too much from the $\mathrm{CC}$ curve. This is analyzed in (Section 3.3) through comparing the $\mathrm{K}_{\mathrm{cb}}$ and $\mathrm{K}_{\mathrm{e}}$ curves relative to AquaCrop and to SIMDualKc when using the FAO dual $\mathrm{K}_{\mathrm{c}}$ approach. Results became worse when using default parameters in 2008, but not those for 2009, 2010 and 2011. One cannot find a reason for that when knowing that the $\mathrm{CC}$ curves simulated with default parameters show much larger errors than those using calibrated values (Table 5). This is probably due to internal adjustments of the model not open to the users.

Results of the "goodness-of-fit" indicators relative to the ASW simulations when using default and calibrated parameters are presented in Table 6 together with results obtained by Wei et al. (2015) when using SIMDualKc. After AquaCrop calibration, the determination coefficients vary in a wide range, indicating that the variability of the ASW observations is not well captured by the model. Errors are generally relatively small but RMSE may reach 24 $\mathrm{mm}$ and ARE can attain $14.1 \%$. The regression coefficients are around 1.0 but these b values mask the over-estimation of ASW in the first half of the season and the under-estimation in 
indicating that the residuals variance was larger than the measured data variance; on the

370 contrary, the other data sets had positive EF indicating that the residuals variance was lower 371 than the measured data variance. Differently, the "goodness-of-fit" indicators relative to

372 SIMDualKc are overall better than those reported for AquaCrop, particularly with quite good 373 results for 2010 and 2011 when AquaCrop results are worse (Fig. 2 and Table 6). Thus, the 374 poor simulation results relative to these data sets are not due to some peculiar data 375 combination but to some insufficiency in modelling, likely due to abandoning the FAO well 376 proven approaches and to internal model adjustments that change the parameter values.

377 When using default parameters, some indicators are worse and other are better than using 378 calibrated parameters (Table 6). This fact is tied with problems of calibration because, as 379 discussed by Pereira et al. (2015b), the calibrated parameters such as $\mathrm{K}_{\mathrm{c}, \operatorname{Tr} \mathrm{x}}$, or the $\mathrm{CC}_{\mathrm{x}}$ 380 parameters, are internally changed by the model. This fact identifies a difficulty in the use of 381 the model because the user has no control on the parameterization and/or calibration 382 processes. Thus, overall, the indicators of "goodness-of-fit" of the AquaCrop model using 383 calibrated or default parameters failed the limits for $\mathrm{R}^{2}$ and $\mathrm{EF}$, respectively 0.80 and 0.70 , 384 proposed by Ma et al. (2011) for agricultural models.

\subsection{ET partitioning and evaporation and transpiration crop coefficients}

Fig. 3 presents examples of the daily variation of the crop coefficients under standard conditions $\left(\mathrm{K}_{\mathrm{cb}}\right.$ and $\left.\mathrm{K}_{\mathrm{c}, \mathrm{Tr}}\right)$, adjusted to water stress $\left(\mathrm{K}_{\mathrm{cb}}\right.$ act and $\left.\mathrm{K}_{\mathrm{c}, \mathrm{Tr} \text { act }}\right)$ as well as the evaporation coefficient $\left(\mathrm{K}_{\mathrm{e}}\right)$ relative to the same data sets of Fig. 2 estimated with AquaCrop and SIMDualKc. The pictures relative to AquaCrop include the crop coefficient and

390 evaporation curves computed with calibrated and default parameters aiming at explaining the 391 simulation results in Fig. 2. Rainfall and irrigation are represented in the pictures relative to 392 the $\mathrm{K}_{\mathrm{cb}}$ and $\mathrm{K}_{\mathrm{e}}$ curves computed with SIMDualKc. 
Fig. 3 clearly shows the differences in $\mathrm{K}_{\mathrm{cb}}$ curves by SIMDualKc, following the linear shaped crop coefficients curve assumed in FAO56 (Allen et al., 1998); in contrast with those derived with AquaCrop, where the $\mathrm{K}_{\mathrm{c}, \operatorname{Tr}}$ curves consist of curvilinear shaped curves proportional to the $\mathrm{CC}$ curve (e.g., Fig. 1). Thus, Fig. 3 clearly show that AquaCrop nearly abandoned the FAO " $\mathrm{K}_{\mathrm{c}}-\mathrm{ET}_{\mathrm{o}}$ " approach despite, as discussed by Pereira et al. (2015a), its simplicity, accuracy and common application.

In AquaCrop, the crop coefficients curves are built using a daily modified $\mathrm{K}_{\mathrm{c}, \operatorname{Tr}}$ that 400 depends upon the CC adjusted for micro-advection and of the $K_{c, T r}$, that is the $K_{c, T r}$ value when $\mathrm{CC}=100 \%$. The model internally adjusts $\mathrm{K}_{\mathrm{c}, \operatorname{Tr} \mathrm{x}}$ when the actual $\mathrm{CC}<100 \%$ and, as previously discussed, the model internally adjusts $\mathrm{CC}_{\mathrm{x}}$ without apparent reason. In SIMDualKc, differently, the $\mathrm{K}_{\mathrm{cb}}$ curves are built taking into consideration the $\mathrm{K}_{\mathrm{cb}}$ values for the initial $\left(\mathrm{K}_{\mathrm{cb} \text { ini }}\right)$, mid ( $\left.\mathrm{K}_{\mathrm{cb} \text { mid }}\right)$ and end $\left(\mathrm{K}_{\mathrm{cb} \text { end }}\right)$ stages, with $\mathrm{K}_{\mathrm{cb} \text { mid }}$ and $\mathrm{K}_{\mathrm{cb} \text { end }}$ adjusted for 405 climate (Allen et al., 1998, 2005) and for crop density using the observed fraction of ground cover and plant height (Allen and Pereira, 2009; Rosa et al., 2012). The referred different approaches are the cause for the different crop coefficient curves represented in Fig. 3.

The calibrated $\mathrm{K}_{\mathrm{c}, \operatorname{Tr} \mathrm{x}}$ was 1.12 (Table 4), that is higher than $\mathrm{K}_{\mathrm{cb} \text { mid }}=1.05$ obtained by Wei 409 et al. (2015) when calibrating SIMDualKc for the same observation data sets. The difference 410 is explained by the fact that $\mathrm{K}_{\mathrm{cb} \text { mid }}$ refers to the entire mid season while $\mathrm{K}_{\mathrm{c}, \operatorname{Tr} \mathrm{x}}$ is the maximum value of $\mathrm{K}_{\mathrm{c}, \mathrm{Tr}}$ for $\mathrm{CC}=100 \%$. In Fig. $3 \mathrm{~K}_{\mathrm{cb} \text { mid }}<1.05$ because it is adjusted to climate and to crop density. AquaCrop did not compute any stress resulting that the $\mathrm{K}_{\mathrm{c}, \mathrm{Tr}}$ and $\mathrm{K}_{\mathrm{c}, \mathrm{Tr} \text { act }}$ curves are coincident. Differently, SIMDualKc adjusted $\mathrm{K}_{\mathrm{cb}}$ for any occasion when a 414 stress occurred, in the present application for only short periods (Fig. 3b, d and f). Results 415 show that $\mathrm{K}_{\mathrm{c}, \operatorname{Tr}}$ during the mid-season was higher than $\mathrm{K}_{\mathrm{cb}}$ due to the higher $\mathrm{K}_{\mathrm{c}, \operatorname{Tr} \mathrm{x}}$ adopted. 416 The calibration could have selected a smaller $K_{c, \operatorname{Tr} \times}$ but this would lead to poor results for 417 biomass and yield predictions since the various model parameters are interlinked. In addition, 
as discussed by Pereira et al. (2015b) the procedure relative to the internal adjustment of

$419 \mathrm{~K}_{\mathrm{c} \operatorname{Tr} \mathrm{x}}$ for every crop having $\mathrm{CC}<100 \%$, should be revised since it makes this calibration a difficult task with insufficient control by the user.

The soil evaporation coefficient $\mathrm{K}_{\mathrm{e}}$ (Fig. 3) is highest during the initial stage, keeps high but decreasing during the crop development stage, and becomes small during the mid season, when the soil is well covered by the crop, increasing again but few during the late season. This behavior is common to both models and all crop seasons. Numerous peaks are shown as responses to soil wettings by precipitation. However, there are differences between the $\mathrm{K}_{\mathrm{e}}$ values computed with both models. During the initial and crop development stages, $\mathrm{K}_{\mathrm{e}}$ from AquaCrop are higher than $\mathrm{K}_{\mathrm{e}}$ from SIMDualKc (Fig. 3). By the mid- and late-season, when

428 the maximum $\mathrm{f}_{\mathrm{c}}$ or $\mathrm{CC}$ is attained, AquaCrop computes generally lower $\mathrm{K}_{\mathrm{e}}$ values and less $\mathrm{K}_{\mathrm{e}}$ 429 peaks than SIMDualKc, thus showing a poor reaction to the precipitation or irrigation events occurring then. The referred differences in $\mathrm{K}_{\mathrm{e}}$ results along the crop season are very likely due to the differences in modeling approaches used, as discussed in Section 2.2, included differences in calibration parameters, more exigent in case of SIMDualKc, as previously 433 discussed for a barley application (Pereira et al., 2015b).

When using default parameters the $\mathrm{K}_{\mathrm{c}, \mathrm{Tr}}$ and $\mathrm{K}_{\mathrm{e}}$ values change relative to those computed 435 when calibrated values were used. This is expected since base parameters used in computations are different; the $\mathrm{K}_{\mathrm{c}, \mathrm{Tr}}$ curve is shifted down and to the right (Fig. 3a, c, e, g)

437 similarly to the shift of the CC curve (Fig. 1). The $\mathrm{K}_{\mathrm{e}}$ peaks are about the same during the 438 initial stage but are increased when the $\mathrm{K}_{\mathrm{c}, \mathrm{Tr}}$ curves obtained with default values are below 439 those computed with calibrated parameters. However, this behavior does not justify the 440 upward or downward shifts of the ASW simulation with default parameters in Figs 2 a, c, e, 441 and g or in "goodness-of-fit" indicators in Table 6. 
Figure $3 \mathrm{a}$ and $\mathrm{b}$ shows that $\mathrm{K}_{\mathrm{c}, \mathrm{Tr}}$ values are very different of the $\mathrm{K}_{\mathrm{cb}}$ values resulting in $443 \mathrm{~T}_{\mathrm{a}}=\mathrm{K}_{\mathrm{c}, \mathrm{Tr}_{\mathrm{r}}} \mathrm{ET}_{\mathrm{o}}$ much smaller than $\mathrm{T}_{\mathrm{c}}=\mathrm{K}_{\mathrm{cb}} \mathrm{ET}_{\mathrm{o}}$ during the initial and first part of the crop 444 development stages, when $\mathrm{K}_{\mathrm{e}}$ from AquaCrop were larger than for SIMDualKc. It resulted $445\left(\mathrm{~K}_{\mathrm{e}}+\mathrm{K}_{\mathrm{c}, \mathrm{Tr}}\right)$ likely smaller than $\left(\mathrm{K}_{\mathrm{cb}}+\mathrm{K}_{\mathrm{e}}\right)$ during this period, thus less water use by then, 446 which may explain the corresponding over-estimation of ASW (Fig. 2). For the last part of the 447 crop development and the mid-season $\mathrm{K}_{\mathrm{c}, \mathrm{Tr}}$ is larger than $\mathrm{K}_{\mathrm{cb}}$ while $\mathrm{K}_{\mathrm{e}}$ is reduced. Thus $\left(\mathrm{K}_{\mathrm{e}}+\right.$ $\left.448 \mathrm{~K}_{\mathrm{c}, \mathrm{Tr}}\right)$ become larger than $\left(\mathrm{K}_{\mathrm{cb}}+\mathrm{K}_{\mathrm{e}}\right)$ and the over-estimation of ASW turns into an 449 underestimation. During the late-season, $\left(\mathrm{K}_{\mathrm{e}}+\mathrm{K}_{\mathrm{c}, \mathrm{Tr}}\right)$ keep larger than $\left(\mathrm{K}_{\mathrm{cb}}+\mathrm{K}_{\mathrm{e}}\right)$. Therefore, 450 there is a trend for $\mathrm{ET}_{\mathrm{c} \text { act }}=\left(\mathrm{K}_{\mathrm{e}}+\mathrm{K}_{\mathrm{c}, \mathrm{Tr}}\right) \mathrm{ET}_{\mathrm{o}}$ to be initially under-estimated, thus leading to a 451 small soil water depletion and, therefore, to an over-estimation of ASW during the first half of 452 the crop season. ET $_{\mathrm{c}}$ act becomes progressively higher and likely over-estimated in the second 453 half of the crop season when, due to increased water depletion, ASW becomes underestimated. This behavior is apparent for all cases in Fig. 2 but over- and under-estimations vary in intensity, which is not explained with results in Fig. 3. Moreover, the behavior of the model when using default parameters, which produce $\mathrm{K}_{\mathrm{c}, \mathrm{Tr}}$ curves with much smaller values, is not explainable. It may depend upon internal adjustments unknown for the user. In our condition of model users, we just consider necessary a deep change in procedures and a better control of the parameterization by the users. Otherwise, the soil water computations should be used only for BWP* calibration aiming at biomass and yield predictions.

\subsection{Soil evaporation testing}

The AquaCrop model was tested for soil evaporation computed with Eq. 2 compared with microlysimeter observations of soil evaporation (Fig. 4). $E_{\mathrm{s}}$ simulations show that the model tends to under-estimate microlysimeter observation data, especially during the mid- and lateseason. This type of behaviour was expected because microlysimeter evaporation is higher than soil evaporation since the latter is affected by water uptake by roots active in the 
evaporative soil layer while those roots do not exist in the microlysimeters. A similar

468 behaviour was observed by Wei et al. (2015) when using SIMDualKc but under-estimations were smaller (Fig. 4). Relative to other crops, under-estimations of lysimeter observations were reported by Klocke et al. (1990, 1996), Jara et al. (1998) and, for maize in the same 471 experimental area, by Zhao et al. (2013). In addition to under-estimations, a large variability 472 of $E_{\mathrm{s}}$ measured values is commonly reported.

473 The larger under-estimations by AquaCrop relative to SIMDualKc may be explained by different approaches relative to $\mathrm{E}_{\mathrm{s}}$ computations, mainly referring to the reduction coefficient $\mathrm{K}_{\mathrm{r}}$ (previously discussed in Section 2.2) since the $\mathrm{K}_{\mathrm{e}}$ values computed by both models do not show large differences as analysed before (Section 3.3). The limitations of $\mathrm{E}_{\mathrm{s}}$ estimation by AquaCrop were discussed by Pereira et al. (2015b) for a barley application under contrasting wetness and dryness conditions.

Table 7 presents the results of the "goodness-of-fit" indicators of the $\mathrm{E}_{\mathrm{s}}$ estimations when using both models. Results show that, after calibration, AquaCrop presents a clear tendency for under-estimation of $E_{s}$, with lower values of $b$ for 2010 and 2011, which are the seasons 482 when most observations were performed during mid and late seasons (Fig. $4 \mathrm{~d}$ and e). These 483 seasons were those where worse results were obtained for simulating ASW as reported in 484 Section 3.2. This may indicate that when $\mathrm{E}_{\mathrm{s}}$ is largely underestimated, particularly in those seasons, the simulation of ASW is also under-estimated (see Figs. 2e and g). In these years, $\mathrm{R}^{2}$ varied in a wide range, thus reflecting a bias in the estimation, particularly during the 487 second half of the crop season. Consequently, errors are high, both RMSE and ARE; 488 however, RMSE are smaller in 2010 and 2011 relative to 2008 and 2009, which likely depend 489 from the size of observations, which was larger in the later years because they largely refer to 490 the periods when the canopy cover was low and $\mathrm{E}_{\mathrm{s}}$ were large (Figs $4 \mathrm{a}, \mathrm{b}$ and $\mathrm{c}$ ). As expected, 
the EF values are smaller for 2010 and 2011 because the referred under-estimation of $\mathrm{E}_{\mathrm{s}}$ leads

492 to larger residual's variance.

493 Less expected are the results when default values were used with AquaCrop. For 2008 and 4942009 results on $\mathrm{R}^{2}$, RMSE, ARE and EF are similar to those relative to using calibrated 495 parameters but $\mathrm{b}$ values indicate a tendency for over-estimation of $\mathrm{E}_{\mathrm{s}}$. In contrast, for 2010 496 and 2011, larger RMSE and smaller ARE values were obtained, as well as an important over497 estimation with $b=1.41$ for 2011. Low EF values resulted, with a negative value for 2011 . 498 The contrast between results for 2011 when using calibrated or default values is enormous in 499 terms of $b$ values, RMSE and EF values. This explains why simulations of ASW in 2011 were 500 also contrasting, with worse results when using calibrated parameters (Table 6). This 501 behaviour is therefore associating the ASW simulation with the $\mathrm{E}_{\mathrm{s}}$ estimation, thus indicating 502 that better ASW simulation results are obtained when $\mathrm{E}_{\mathrm{s}}$ values are high during the mid- and late-season since a worse ASW under-estimation occurs during these crop stages. This identifies a problem in the computation of $\mathrm{E}_{\mathrm{s}}$, as already discussed by Pereira et al. (2015b), that may relate to the already discussed mechanistic approach used for computing the reduction coefficient $K_{r}\left(\right.$ Section 2.2). Thus, it is advisable that model developers revise the $E_{s}$ 507 estimation procedures.

508 When using the SIMDualKc model, results presented by Wei et al. (2015) show a slight 509 tendency for under-estimation, particularly during 2010 (Table 7). As previously pointed out, 510 under-estimation is likely due the fact that most of $E_{s}$ observations were performed during 511 mid and late seasons when microlysimeters are expected to evaporate more than the 512 surrounding soil where, in addition to evaporation, water is also extracted by crop roots. The 513 RMSE and ARE values are smaller than those by AquaCrop (Table 7) while $\mathrm{R}^{2}$ and EF values 514 are consistently higher. These good results evidence the goodness of the FAO dual Kc 515 approach relative to the $\mathrm{E}_{\mathrm{s}}$ estimation. 
Table 8 presents the results of comparing AquaCrop and SIMDualKc simulated $\mathrm{E}_{\mathrm{s}}$ and

$517 \mathrm{E}_{\mathrm{s}} / \mathrm{ET}_{\mathrm{c}}$ act for the various crop stages and all seasons and treatments. During the initial stage, 518 the ratios $\mathrm{E}_{\mathrm{s}} / \mathrm{ET}_{\mathrm{c} \text { act }}$ computed with AquaCrop are consistently higher than those obtained 519 with SIMDualKc, however with small differences in terms of the $\mathrm{E}_{\mathrm{s}}$ amount (Fig. 3), which is 520 even smaller in case of AquaCrop for the 2008-T1 and 2009 experiments. This behaviour 521 results from an underestimation of the transpiration during that period because $\mathrm{T}_{\mathrm{a}}$ is computed 522 from CC (Eq. 1), which is extremely small during the initial crop stage. It results, therefore, a 523 very large proportion of $\mathrm{E}_{\mathrm{s}}$ relative to $\mathrm{ET}_{\mathrm{c} \text { act }}$, ranging 91 to $97 \%$ while that percentage varies 72 to $85 \%$ with SIMDualKc. These results indicate that $T_{a}$ are under-estimated by AquaCrop during the initial crop stage.

During the crop development stage, the $\mathrm{E}_{\mathrm{s}}$ values simulated with AquaCrop were smaller than those obtained with SIMDualKc in the last part of this crop stage (Fig. 3), with the ratios $\mathrm{E}_{\mathrm{s}} / \mathrm{ET}_{\mathrm{c} \text { act }}$ consistently smaller (Table 8 ). This may be due to an overestimation of $\mathrm{T}_{\mathrm{a}}$ during that same period as discussed in the precedent Section. During mid-season the same trend is observed but with a very low $\mathrm{E}_{\mathrm{s}}$ and $\mathrm{E}_{\mathrm{s}} / \mathrm{ET}_{\mathrm{c} \text { act }}$ values computed with AquaCrop, also consistently smaller than for SIMDualKc (Table 8 and Fig. 4). These differences are coherent 532 relative to results in Fig. 3, previously discussed. The tendency of AquaCrop for under 533 estimating $\mathrm{E}_{\mathrm{s}}$ was maintained during the late-season (Fig. 4), excepting for the crop season of 2009 , which is also likely related to the same insufficiencies in describing the $\mathrm{K}_{\mathrm{c}, \mathrm{Tr}}$ curve discussed in Section 3.3. Consequently, for all crop seasons, the total evaporation depths and 536 the ratios $\mathrm{E}_{\mathrm{s}} / \mathrm{ET}_{\mathrm{c} \text { act }}$ are consistently smaller when computed with AquaCrop (Table 8). The 537 difference was higher for the T2-2010 data set, with AquaCrop computing almost half of the $538 \mathrm{E}_{\mathrm{s}}$ computed by SIMDualKc. Therefore, it is likely that $\mathrm{E}_{\mathrm{s}}$ computations when the canopy cover is complete or is near completion are too much depending on $\mathrm{CC}$ and little on the soil evaporative characteristics, i.e., the respective parameterization, referred before, is insufficient 
541 relative to that proposed by Allen et al. (1998; 2005) and adopted in SIMDualKc (Rosa et al., 542 2012). Conclusions reported by Farahani et al. (2009), Katerji et al. (2013), and Paredes et al. 543 (2014b), as well as the analysis by Pereira et al. (2015b), show that the procedures for 544 estimation of $\mathrm{E}_{\mathrm{s}}$ in AquaCrop are questionable and should be improved.

\section{3.5. Soybean biomass and yield predictions}

546 The observed final harvested biomass (B) and yield $\left(\mathrm{Y}_{\mathrm{a}}\right)$ used to test the AquaCrop 547 predictions are presented in Table 9. The highest yield was obtained with the treatment $\mathrm{T} 1$ in $5482010\left(4230 \mathrm{~kg} \mathrm{ha}^{-1}\right)$ while the lowest refers to $2011\left(3222 \mathrm{~kg} \mathrm{ha}^{-1}\right)$. Differences in yield may 549 be partially explained by differences in climatic conditions along the crop seasons. Since 550 radiation and temperature averages along those referred crop seasons are very similar (Table 551 1), differences in $Y_{a}$ may relate to the diurnal and nocturnal temperatures as discussed by Tao 552 et al. (2008) relative to the Hebei province or as reported by Puteh et al. (2013) for Malaysia, 553 namely referring to high temperature stress during the reproductive growth stage. Differences in crop management may also have contributed to differences in yield.

AquaCrop predictions of both biomass and yield when using only default parameters show a clear trend for under-estimation, with deviations higher than $27 \%$ and $20 \%$ of the observed

557 final biomass and yield, respectively (Table 9). In contrast, when the model was appropriately 558 calibrated the deviations between observed and predicted biomass were much small, generally 559 smaller than $9 \%$. Relative to the final yield, deviations were below $8.6 \%$ except for two cases, when they were of 11.8 and $12.9 \%$. Results may be considered excellent for 2008 and 2009 and reasonably good for 2010 and 2011. It may be noticed that these results relate with the

562 quality of soil water simulations, not good for 2010 and 2011 (Fig. 2 and Table 6). The worse $563 \mathrm{~B}$ and $\mathrm{Y}_{\mathrm{a}}$ results may have been influenced by the difficulties in achieving a good partition of $\mathrm{ET}_{\mathrm{c} \text { act }}$, with poor estimation of $\mathrm{E}_{\mathrm{s}}$ and $\mathrm{T}_{\mathrm{a}}$, the latter contributing to the estimation of $\mathrm{B}$ and $\mathrm{Y}_{\mathrm{a}}$. 565 Nevertheless, if good $\mathrm{B}$ and $\mathrm{Y}_{\mathrm{a}}$ estimations could be achieved this is due to the satisfactory 
calibration of BWP*, which highly influences biomass and yield estimation. One may

567 hypothesize that if a better estimation of $\mathrm{E}_{\mathrm{s}}$ and $\mathrm{T}_{\mathrm{a}}$ could be achieved also better estimations 568 of the final biomass and yield would have been attained.

569 The biomass RMSE is $1056 \mathrm{~kg} \mathrm{ha}^{-1}$, which represent less than $12 \%$ of the observed final 570 biomass while for the final yield it was quite low, $302 \mathrm{~kg} \mathrm{ha}^{-1}$, thus representing $8 \%$ of the 571 averaged observed yield. Results fall within the category of "very good modelling results" as 572 proposed by Hanson et al. (1999) since the deviations were lower than $15 \%$ of the observed 573 values except for one prediction of B. Despite the low accuracy of the ASW simulations, 574 indicative of poor $\mathrm{E}_{\mathrm{s}}$ and $\mathrm{T}_{\mathrm{a}}$ estimation, yield predictions could be very good due to an 575 appropriate BWP* calibration. If default parameters are used then B and $\mathrm{Y}_{\mathrm{a}}$ estimations have 576 much larger errors, probably not acceptable for most applications.

577 Similar yield predictions, with RMSE $=381 \mathrm{~kg} \mathrm{ha}^{-1}$, were obtained by Wei et al. (2015) 578 with the same data sets but using the Stewarts' model combined with the SIMDualKc model, 579 however with a larger over-prediction. Using the CROPGRO-soybean model, Calviño et al. 580 (2003) reported RMSE $=512 \mathrm{~kg} \mathrm{ha}^{-1}$, i.e., approximately $18 \%$ of the average observed $\mathrm{Y}_{\mathrm{a}}$, 581 while Liu et al. (2013) found RMSE representing 15 to $22 \%$ of the average $Y_{a}$ in Northeast 582 China. Stöckle et al. (2003) applied the CropSyst model and reported RMSE corresponding to $58314 \%$ of the average $\mathrm{Y}_{\mathrm{a}}$. Mohanty et al. (2012) when using the APSIM model reported an 584 under-estimation of only $100 \mathrm{~kg} \mathrm{ha}^{-1}$, i.e., less than $6 \%$ of $\mathrm{Y}_{\mathrm{a}}$. Overall, results of the present 585 study fall within the reported soybean applications, thus indicating that AquaCrop may be 586 further used for yield predictions when appropriately calibrated.

\section{Conclusions}

588 The AquaCrop model was parameterized using four years of field observations of a soybean crop in the North China Plain. The model was tested using default and calibrated parameters and compared with the soil water balance model SIMDualKc (Wei et al., 2015), that was 
calibrated and validated with the same data sets on weather, soil and crop data. In addition,

592 microlysimeters data on soil evaporation were used to test the soil evaporation component of 593 the model.

594 Results have shown that an appropriate parameterization of the CC curve contributed to 595 better simulating the available soil water and soil evaporation, as well as to improve biomass 596 and yield predictions. The AquaCrop model has shown, however, a lower accuracy for 597 simulating the soil water content along the crop seasons. This reveals a model insufficiency 598 since using calibrated instead of default parameters lead to small differences in performance, 599 which was sometimes in favour of default parameters. Results have shown a bias in the 600 estimation of ASW, with a tendency for over-estimation during the first half of the season and 601 under-estimation during the other half. This resulted from the $\mathrm{K}_{\mathrm{c}}$ curve used in AquaCrop, as 602 well as the mechanistic approach used for soil evaporation. The insufficiencies in simulating 603 the latter were demonstrated by the consistent under-estimation of the $\mathrm{E}_{\mathrm{s}}$ micro-lysimeter 604 data.

605 When comparing AquaCrop with SIMDualKc results show the higher accuracy of the 606 latter for simulating ASW and $\mathrm{E}_{\mathrm{s}}$, which was demonstrated by the "goodness-of-fit" results 607 achieved. Since SIMDualKc uses the FAO56 dual $\mathrm{K}_{\mathrm{c}}$ approach, its good results, namely 608 referring to partitioning crop evapotranspiration, are due to the accuracy of that approach, 609 following good results reported by several researchers as recently revised by Kool et al. 610 (2014) and Pereira et al. (2015a). In contrast, the abandon of the FAO56 dual $\mathrm{K}_{\mathrm{c}}$ approach by 611 the FAO AquaCrop model was not properly tested through specific and focused studies, thus 612 resulting in poor ET partition and soil water simulations. Therefore, in agreement with other 613 studies (Katerji et al., 2013; Pereira et al., 2015b), we conclude that AquaCrop is not suitable 614 to be used for irrigation scheduling purposes prior to its improvement. Very likely, as also 
615 referred by those authors, since AquaCrop abandoned the dual $\mathrm{K}_{\mathrm{c}}$ approach it should also

616 abandon the " $\mathrm{K}_{\mathrm{c}}-\mathrm{ET}_{\mathrm{o}}$ " methodology and assume a fully mechanistic approach.

617 Good final biomass and yield estimations were achieved, particularly due to the

618 satisfactory calibration of BWP*. However, one may hypothesize that if a better estimation of

$619 \mathrm{E}_{\mathrm{s}}$ and $\mathrm{T}_{\mathrm{a}}$ could be achieved also better estimations of the final biomass and yield would have

620 been attained. However, the use of AquaCrop default parameters for yield predictions is 621 questionable since results show a clear tendency for under-estimation. Thus, in the absence of 622 field data the model should be used with caution. In this perspective, priority should be given 623 to improve model predictions with limited parameterization or using default parameters.

\section{Acknowledgements}

Thanks are due to the National Natural Science Foundation of China (91125017, $51109225,51479210)$ for supporting the experimental work. The study was partially funded by the FCT research project PTDC/GEO-MET/3476/2012.

\section{References}

Allen, R.G., Pereira, L.S., 2009. Estimating crop coefficients from fraction of ground cover and height. Irrigation Sci. 28(1): 17-34.

Allen, R.G., Pereira, L.S., Raes, D., Smith, M., 1998. Crop Evapotranspiration. Guidelines for Computing Crop Water Requirements. FAO Irrigation and Drainage Paper 56. FAO, Rome, 300 pp.

Allen, R.G., Pereira, L.S., Smith, M., Raes, D., Wright, J.L., 2005. FAO-56 Dual crop coefficient method for estimating evaporation from soil and application extensions. J. Irrig. Drain. Eng. 131, 213.

Allen, R.G., Wright, J.L., Pruitt, W.O., Pereira, L.S., Jensen, M.E. 2007. Water requirements. In:

637 Hoffman, GJ, Evans, RG, Jensen, ME, Martin, DL, Elliot, RL (eds.) Design and Operation of Farm 638 Irrigation Systems (2nd Edition), ASABE, St. Joseph, MI, pp. 208-288.

639 Bowermann, B.L., O’Connel, R.T., Koehler, A.B., 2005. Forecasting, Time Series and Regression. An 640 Applied Approach. $5^{\text {th }}$ Edition, Thomson Brooks/Cole, Belmont, CA, 684 pp.

641 Calviño, P.A., Sadras, V.O., Andrade, F.H., 2003. Quantification of environmental and management effects on the yield of late-sown soybean. Field Crop. Res. 83: 67-77 
Cui, S. Y., Yu D. Y., 2005. Estimates of relative contribution of biomass, harvest index and yield components to soybean yield improvements in China. Plant Breeding 124: 473-476

Donatelli, M., Stöckle C., Ceotto E., Rinaldi M., 1997. Evaluation of CropSyst for cropping systems at two locations of northern and southern Italy. Eur. J. Agron. 6: 35-45

Doorenbos, J., Pruitt, W.O., 1977. Guidelines for predicting crop-water requirements. In: FAO Irrigation and Drainage Paper No. 24, second rev. ed. FAO, Rome, Italy, 156 pp.

Farahani, H.J., Izzi, G., Oweis, T., 2009. Parameterization and evaluation of the AquaCrop model for full and deficit irrigated cotton. Agron. J. 101, 469-476.

Hanson, J.D., 1999. Generic Crop Production. In: Ahuja, L., Rojas, K., Hanson, J., Shaffer, M., Ma, M. (Eds.), RZWQM. Modeling management effects on water quality and crop production. Water Resources Publications, LLC, CO, USA, pp. 81-118.

Jara, J., Stockle, C.O., Kjelgaard, J., 1998. Measurement of evapotranspiration and its components in a corn (Zea mays L.) field. Agr. Forest Meteorol. 92, 131-145.

Katerji, N., Campi, P., Mastrorilli, M., 2013. Productivity, evapotranspiration, and water use efficiency of corn and tomato crops simulated by AquaCrop under contrasting water stress conditions in the Mediterranean region. Agric. Water Manage. 130, 14-26.

Klocke, N.L., Martin, D.L., Todd, R.W., DeHaan, D.L., Polymenopoulos, A.D., 1990. Evaporation measurements and predictions from soils under crop canopies. Trans. of the ASAE 33, 1590-1596.

Klocke, N.L., Todd, R.W., Schneekloth, J.P., 1996. Soil water evaporation in irrigated corn. Appl. Eng. Agric. 12 (3), 301-306.

Kool, D., Agam, N., Lazarovitch, N., Heitman, J.L., Sauer, T.J., Ben-Gal, A., 2014. A review of approaches for evapotranspiration partitioning. Agr. For. Meteorol.184, 56-70.

Kottek, M., Grieser, J., Beck, C., Rudolf, B., Rubel, F. 2006. World Map of the Köppen-Geiger climate classification updated. Meteorol. Z. 15(3), 259-263

Liu, Y., Pereira, L. S., Fernando, R. M., 2006. Fluxes through the bottom boundary of the root zone in silty soils: parametric approaches to estimate groundwater contribution and percolation. Agric. Water Manage. 84, 27-40.

Liu, S., Yang, J.Y., Zhang, X.Y., Drury, C.F., Reynolds, W.D., Hoogenboom, G., 2013. Modelling crop yield, soil water content and soil temperature for a soybean-maize rotation under conventional and conservation tillage systems in Northeast China. Agricultural Water Management 123: 32- 44

Ma, L., Ahuja, L.R., Saseendran, S.A., Malone, R.W., Green, T.R., Nolan, B.T., Bartling, P.N.S., Flerchinger, G.N., Boote, K.J., Hoogenboom. G., 2011. A Protocol for parameterization and calibration of RZWQM2 in field research. In: L.R. Ahuja and L. Ma (Eds). Methods of Introducing System Models into Agricultural Research, ASA, CSSA and SSSA, Madsion, WI, pp. 1-64. 
Mohanty, M., Probert, M.E., Sammi-Reddy K., Dalal, R.C., Mishra, A.K., Subba-Rao, A., Singh, M., Menzies, N.W., 2012. Simulating soybean-wheat cropping system: APSIM model parameterization and validation. Agr. Ecosyst. Environ. 152: 68-78

Nash, J.E., Sutcliffe, J.V., 1970. River flow forecasting through conceptual models: Part 1. A discussion of principles. J. Hydrol. 10(3): 282-290

Paredes, P., Rodrigues, G. C., Alves, I., Pereira, L. S., 2014a. Partitioning evapotranspiration, yield prediction and economic returns of maize under various irrigation management strategies. Agric. Water Manage. 135, 27-39

Paredes, P, de Melo-Abreu, J.P., Alves, I., Pereira, L.S., 2014b. Assessing the performance of the FAO AquaCrop model to estimate maize yields and water use under full and deficit irrigation with focus on model parameterization. Agric. Water Manage. 144, 81-97

Pereira L. S., Cai L. G., Hann M. J., 2003. Farm water and soil management for improved water use in the North China Plain. Irrig. Drain. 52(4): 299-317.

Pereira L.S., Allen R.G., Smith M., Raes D., 2015a. Crop evapotranspiration estimation with FAO56: Past and future. Agric. Water Manage. 147, 4-20,

Pereira, L.S., Paredes, P., Rodrigues, G.C., Neves, M., 2015b. Modeling barley water use and evapotranspiration partitioning in two contrasting rainfall years. Assessing SIMDualKc and AquaCrop models. Agric. Water Manage. (submitted)

Puteh, A.B., ThuZar, M., Mondal, M.M.A., Abdullah, N.A.P.B., Halim, M.R.A., 2013. Soybean [Glycine max (L.) Merrill] seed yield response to high temperature stress during reproductive growth stages. Aust. J. Crop Sci. 7(10):1472-1479

Raes, D., Geerts, S., Kipkorir, E., Wellens, J., Sahli, A., 2006. Simulation of yield decline as a result of water stress with a robust soil water balance model. Agric. Water Manage. 81(3), 335-357.

Raes, D., Steduto, P., Hsiao, T.C., Fereres, E., 2012. Crop Water Productivity. Calculation Procedures and Calibration Guidance. AquaCrop version 4.0., FAO, Land and Water Development Division, Rome.

Rawls, W.J., Gimenez, D., Grossman, R., 1998. Use of soil texture, bulk density, and slope of the water retention curve to predict saturated hydraulic conductivity. Trans. ASAE 41(4), 983-988.

Ritchie, J.T., 1972. Model for predicting evaporation from a row crop with incomplete cover. Water Resour. Res. 8: 1204-1213

Rosa, R.D., Paredes, P., Rodrigues, G.C., Alves, I., Fernando, R.M., Pereira, L.S, Allen, R.G., 2012. Implementing the dual crop coefficient approach in interactive software: 1. Background and computational strategy. Agr. Water Manage. 103, 8-24.

Steduto, P., Hsiao, T.C., Fereres, E., Raes, D. (Eds.) 2012. Crop Yield Response to Water. FAO Irrigation and Drainage Paper 66, FAO, Rome, Italy, 500 p. 
Stewart, J.I., Hagan, R.M., Pruitt, W.O., Danielson, R.E., Franklin, W.T., Hanks, R.J., Riley, J.P., 713 Jackson, E.B., 1977. Optimizing crop production through control of water and salinity levels in the 714 soil. Reports. Paper 67. Utah Water Research Laboratory, USA, 191 p

715 Stöckle, C.O., Donatelli, M., Nelson, R., 2003. CropSyst, a cropping systems simulation model. Eur. J. 716 Agronomy, 18: 289-307.

717 Tao, F., Yokozawa, M., Liu, J., Zhang, Z., 2008. Climate-crop yield relationships at provincial scales 718 in China and the impacts of recent climate trends. Clim. Res. 38, 83-94

719 Wang, D-G., Hu, G.-Y., Li, J.-K., Huang, Z.-P., Yu, G.-Y., Zhang, L., 2013. A preliminary report on 720 the study of maturity

721 y group classification of soybean varieties (lines) in Huang-Huai. Soybean Science, 32(5): 629-634 (in 722 Chinese)

723 Wei, Z., Paredes, P., Liu, Y., Chi, W.W., Pereira, L.S., 2015. Modelling transpiration, soil evaporation 724 and yield prediction of soybean in North China Plain. Agric. Water Manage. 147, 43-53.

725 Yan, X., 2007. Root Biology: Principles and Applications, Science Press, Beijing. (in Chinese).

726 Zhao, N., Liu, Y., Cai, J.B., Paredes, P., Rosa, R.D., Pereira, L.S., 2013. Dual crop coefficient 727 modelling applied to the winter wheat-summer maize crop sequence in North China Plain: Basal 728 crop coefficients and soil evaporation component. Agr. Water Manage. 117, 93-105 
Average relative error (\%)

734 ASW

Available soil water ( $\mathrm{mm})$

735 B

Above ground dry biomass ( $\left.\mathrm{t} \mathrm{ha}^{-1}\right)$

736 b

Regression coefficient (non-dimensional)

737 BWP*

Biomass (water) productivity adjusted for $\mathrm{ET}_{\mathrm{o}}$ and $\mathrm{CO}_{2}\left(\mathrm{~g} \mathrm{~m}^{-2}\right)$

$738 \mathrm{CC}$

$739 \mathrm{CC}^{*}$

Green canopy cover (\%)

$740 \quad \mathrm{CC}_{\mathrm{o}}$

Actual crop canopy cover adjusted for micro-advective effects (\%)

$741 \quad \mathrm{CC}_{\mathrm{x}}$

Canopy cover at $90 \%$ of emergence $\left(\mathrm{cm}^{2}\right.$ per plant)

$742 \quad \mathrm{CDC}$

Maximum green canopy cover $(\%)$

743 CGC

Canopy decline coefficient $\left(\% \mathrm{GDD}^{-1}\right.$ or $\% \mathrm{day}^{-1}$ )

744 CGDD

Canopy growth coefficient $\left(\% \mathrm{GDD}^{-1}\right.$ or $\%$ day $\left.^{-1}\right)$

$745 \mathrm{CN}$

Cumulative growing degree days $\left({ }^{\circ} \mathrm{C}\right)$

$746 \quad \mathrm{CR}$

Curve number (non-dimensional)

747 DP

Capillary rise from shallow water table $(\mathrm{mm})$

748 EF

Deep percolation $(\mathrm{mm})$

$749 \quad \mathrm{E}_{\mathrm{s}}$

750 ET

Modelling efficiency (non-dimensional)

Soil evaporation (mm)

$751 \quad \mathrm{ET}_{\mathrm{c}}$

$752 \quad \mathrm{ET}_{\mathrm{c} \text { act }}$

crop evapotranspiration ( $\mathrm{mm}$ )

$753 \quad \mathrm{ET}_{\mathrm{d}}$

Standard (non-stressed) crop evapotranspiration (mm)

$754 \quad \mathrm{ET}_{\mathrm{o}}$

$755 \quad \mathrm{f}_{\mathrm{c}}$

$756 \mathrm{f}_{\mathrm{ew}}$

Adjusted or actual crop evapotranspiration ( $\mathrm{mm}$ )

$757 \quad \mathrm{f}_{\mathrm{K}}$

Crop evapotranspiration deficit (mm)

Reference evapotranspiration (mm)

Fraction of soil cover by vegetation (non-dimensional)

Fraction of soil wetted and exposed to solar radiation (non-dimensional)

Decline factor (non-dimensional)

758 GDD

Growing degree days $\left({ }^{\circ} \mathrm{C}\right)$

$759 \quad \mathrm{HI}_{\mathrm{o}}$

$760 \quad \mathrm{~K}_{\mathrm{c}}$

Reference harvest index (\%)

$761 \quad \mathrm{~K}_{\mathrm{c} \max }$

Crop coefficient (non-dimensional)

$762 \quad \mathrm{~K}_{\mathrm{cb}}$

$763 \quad \mathrm{~K}_{\mathrm{cb} \text { act }}$

Maximum value of crop coefficient (following rain or irrigation) (non-dimensional)

$764 \quad \mathrm{~K}_{\mathrm{cb} \text { end }}$

Basal crop coefficient (non-dimensional)

Actual or adjusted basal crop coefficient (non-dimensional)

$765 \quad \mathrm{~K}_{\mathrm{cb} \text { ini }}$

Basal crop coefficient at end of the late season growth stage (non-dimensional)

$766 \quad \mathrm{~K}_{\mathrm{cb} \text { mid }}$

Basal crop coefficient during the initial growth stage (non-dimensional)

$767 \quad \mathrm{~K}_{\mathrm{c} \max }$

Basal crop coefficient during the mid-season growth stage (non-dimensional)

Maximum value of the crop coefficient $\left(\mathrm{K}_{\mathrm{c}}\right)$ following rain or an irrigation event (non-

$769 \quad \mathrm{~K}_{\mathrm{c}, \operatorname{Tr}}$ dimensional)

$770 \quad \mathrm{~K}_{\mathrm{c}, \text { Tr act }}$

Crop transpiration coefficient (non-dimensional)

$771 \quad \mathrm{~K}_{\mathrm{c}, \operatorname{Tr} \mathrm{x}}$

Actual crop transpiration coefficient (non-dimensional)

$772 \quad \mathrm{~K}_{\mathrm{ex}}$

Maximum standard crop transpiration coefficient (non-dimensional)

Soil evaporation coefficient for fully wet and non-shaded soil surface (non-

dimensional)

$774 \quad \mathrm{~K}_{\mathrm{d}}$

Density coefficient (non-dimensional)

$775 \quad \mathrm{~K}_{\mathrm{r}}$

Evaporation reduction coefficient (non-dimensional) 


$\begin{array}{lll}776 & \mathrm{~K}_{\mathrm{s}} & \text { Water stress coefficient (non-dimensional) } \\ 777 & \mathrm{~K}_{\mathrm{sat}} & \text { Saturated hydraulic conductivity }\left(\mathrm{cm} \mathrm{d}^{-1}\right) \\ 778 & \mathrm{~K}_{\mathrm{y}} & \text { Yield response factor (non-dimensional) } \\ 779 & \text { LAI } & \text { Leaf area index }\left(\mathrm{cm}^{2} \mathrm{~cm}^{-2}\right) \\ 780 & \mathrm{R}^{2} & \text { Determination coefficient (non-dimensional) } \\ 781 & \mathrm{RAW} & \text { Readily available soil water }(\mathrm{mm}) \\ 782 & \mathrm{REW} & \text { Readily evaporable soil water }(\mathrm{mm}) \\ 783 & \mathrm{RMSE} & \text { Root mean square error (same units as observations) } \\ 784 & \mathrm{RO} & \text { Runoff (mm) } \\ 785 & \mathrm{RYL} & \text { Relative yield losses }(\%) \\ 786 & \mathrm{~T}_{\mathrm{a}} & \text { Actual transpiration }(\mathrm{mm}) \\ 787 & \mathrm{TAW} & \text { Total (plant) available soil water }(\mathrm{mm}) \\ 788 & \mathrm{~T}_{\mathrm{c}} & \text { Crop transpiration (mm) } \\ 789 & \mathrm{~T}_{\mathrm{d}} & \text { transpiration deficit }(\mathrm{mm}) \\ 790 & \mathrm{TEW} & \text { Total evaporable water }(\mathrm{mm}) \\ 791 & \mathrm{~W}_{\mathrm{rel}} & \text { Relative soil water content }(\%) \\ 792 & \mathrm{Y}_{\mathrm{a}} & \left.\text { Actual yield (t ha }{ }^{-1}\right) \\ 793 & \mathrm{Z}_{\mathrm{e}} & \text { Evaporable layer thickness (m) } \\ 794 & \mathrm{Z}_{\mathrm{r}} & \text { Root depth (m) } \\ 795 & \theta_{\mathrm{FC}} & \text { Volumetric water content at field capacity }\left(\mathrm{m}^{3} \mathrm{~m}^{-3}\right) \\ 796 & \theta_{\mathrm{sat}} & \text { Volumetric water content at saturation }\left(\mathrm{m}^{3} \mathrm{~m}^{-3}\right) \\ 797 & \theta_{\mathrm{WP}} & \text { Volumetric water content at wilting point }\left(\mathrm{m}^{3} \mathrm{~m}^{-3}\right) \\ 798 & & \end{array}$

798

799 
Table 1. Average monthly weather data relative to the soybean season, years 2008-2011.

\begin{tabular}{lllllll}
\hline & Year & Jun & Jul & Aug & Sep & Oct \\
\hline Max. air temperature, ${ }^{\circ} \mathrm{C}$ & 2008 & 27.7 & 31.5 & 30.3 & 25.9 & 20.2 \\
& 2009 & 31.5 & 31.4 & 29.8 & 25.7 & 21.2 \\
& 2010 & 29.3 & 32.7 & 30.7 & 25.5 & 18.5 \\
Min. air temperature, ${ }^{\circ} \mathrm{C}$ & 2011 & 32.0 & 31.6 & 30.4 & 25.2 & 19.5 \\
& 2008 & 17.4 & 21.7 & 20.3 & 14.0 & 6.0 \\
& 2009 & 17.5 & 21.1 & 20.2 & 14.2 & 6.3 \\
Min. Relative Humidity, \% & 2010 & 18.2 & 23.2 & 20.1 & 14.0 & 6.1 \\
& 2011 & 18.8 & 22.1 & 20.6 & 12.3 & 6.0 \\
& 2008 & 63 & 64 & 66 & 64 & 54 \\
Solar radiation, $\mathrm{MJ} \mathrm{m}^{-2} \mathrm{~d}^{-1}$ & 2009 & 44 & 64 & 69 & 65 & 47 \\
& 2010 & 59 & 63 & 63 & 62 & 57 \\
& 2011 & 48 & 66 & 70 & 57 & 60 \\
ET $_{\text {o }}$ mm & 2008 & 21.4 & 21.5 & 19.8 & 15.9 & 11.4 \\
& 2009 & 22.5 & 21.5 & 19.4 & 14.9 & 12.1 \\
& 2011 & 22.3 & 19.4 & 19.0 & 15.2 & 11.2 \\
Precipitation, mm & 22.7 & 20.9 & 20.1 & 16.0 & 11.4 \\
& 2008 & 118 & 132 & 113 & 72 & 42 \\
& 2009 & 147 & 140 & 113 & 70 & 52 \\
& 2010 & 132 & 135 & 115 & 72 & 43 \\
& 2011 & 146 & 137 & 119 & 81 & 40 \\
& 2008 & 103 & 66 & 64 & 123 & 42 \\
& 2009 & 81 & 206 & 104 & 21 & 6 \\
& 2010 & 87 & 42 & 141 & 69 & 32 \\
& 2011 & 72 & 210 & 72 & 33 & 10 \\
\hline
\end{tabular}

Table 2. Average soil hydraulic properties of Daxing experimental fields

\begin{tabular}{llllll}
\hline Layer & Depth $(\mathrm{m})$ & $\theta_{\mathrm{sat}}\left(\mathrm{cm}^{3} \mathrm{~cm}^{-3}\right)$ & $\theta_{\mathrm{FC}}\left(\mathrm{cm}^{3} \mathrm{~cm}^{-3}\right)$ & $\theta_{\mathrm{WP}}\left(\mathrm{cm}^{3} \mathrm{~cm}^{-3}\right)$ & $\mathrm{K}_{\mathrm{sat}}\left(\mathrm{cm} \mathrm{d}^{-1}\right)$ \\
\hline 1 & $0.00-0.10$ & 0.46 & 0.32 & 0.09 & 97.1 \\
2 & $0.10-0.20$ & 0.46 & 0.34 & 0.13 & 91.5 \\
3 & $0.20-0.40$ & 0.47 & 0.35 & 0.10 & 98.5 \\
4 & $0.40-0.60$ & 0.45 & 0.33 & 0.11 & 88.0 \\
5 & $0.60-1.00$ & 0.44 & 0.31 & 0.16 & 37.1 \\
\hline
\end{tabular}

$\theta_{\mathrm{FC}}, \theta_{\mathrm{WP}}$ and $\theta_{\mathrm{Sat}}$ represent the soil water content at field capacity, wilting point and saturation respectively; $\mathrm{K}_{\mathrm{sat}}$ is the saturated hydraulic conductivity. 
Table 3. Soybean crop growth stages dates and cumulative growing degree days (CGDD) for all experimental years.

\begin{tabular}{|c|c|c|c|c|c|}
\hline \multirow{2}{*}{ Crop growth stages } & & \multicolumn{4}{|l|}{ Soybean } \\
\hline & & 2008 & 2009 & 2010 & 2011 \\
\hline \multirow[t]{2}{*}{ Initial } & Dates & $24-06$ to $13-07$ & $14-06$ to $09-07$ & $25-06$ to $18-07$ & $22-06$ to $07-07$ \\
\hline & CGDD $\left({ }^{\circ} \mathrm{C}\right)$ & 372 & 463 & 468 & 302 \\
\hline \multirow[t]{2}{*}{ Crop development } & Dates & $14-07$ to $07-08$ & $10-07$ to $31-07$ & $19-07$ to $20-08$ & $08-07$ to $07-08$ \\
\hline & CGDD $\left({ }^{\circ} \mathrm{C}\right)$ & 910 & 948 & 1163 & 969 \\
\hline \multirow[t]{2}{*}{ Mid-season } & Dates & 08-08 to $16-09$ & $01-08$ to $09-09$ & $21-08$ to $19-09$ & $08-08$ to $13-09$ \\
\hline & CGDD $\left({ }^{\circ} \mathrm{C}\right)$ & 1642 & 1690 & 1713 & 1676 \\
\hline \multirow[t]{2}{*}{ Late Season } & Dates & $17-09$ to $09-10$ & $10-09$ to $02-10$ & $20-09$ to $08-10$ & $14-09$ to $02-10$ \\
\hline & CGDD $\left({ }^{\circ} \mathrm{C}\right)$ & 1898 & 2027 & 1922 & 1872 \\
\hline
\end{tabular}

Table 4. Conservative and calibrated crop parameters of AquaCrop model

\begin{tabular}{|c|c|c|c|c|c|c|}
\hline Description & Units or symbol meaning & Value & & & & \\
\hline Conservative parameters & & Default* & & & & \\
\hline Base temperature & ${ }^{\circ} \mathrm{C}$ & 5 & & & & \\
\hline Cut-off temperature & ${ }^{\circ} \mathrm{C}$ & 30 & & & & \\
\hline $\begin{array}{l}\text { Canopy cover at } 90 \% \text { emergence } \\
\left(\mathrm{CC}_{\mathrm{o}}\right)\end{array}$ & $\mathrm{cm}^{2}$ per plant & 5.00 & & & & \\
\hline $\begin{array}{l}\text { Soil water depletion threshold for } \\
\text { canopy expansion }\end{array}$ & Upper threshold & 0.15 & & & & \\
\hline $\begin{array}{l}\text { Soil water depletion threshold for } \\
\text { canopy expansion }\end{array}$ & Lower threshold & 0.65 & & & & \\
\hline $\begin{array}{l}\text { Shape factor for water stress } \\
\text { coefficient for canopy expansion }\end{array}$ & Curve shape moderately convex curve & 3.0 & & & & \\
\hline $\begin{array}{l}\text { Soil water depletion threshold for } \\
\text { stomatal control }\end{array}$ & $\begin{array}{l}\text { Fraction of TAW at which stomata } \\
\text { start to close }\end{array}$ & 0.50 & & & & \\
\hline $\begin{array}{l}\text { Shape factor for water stress } \\
\text { coefficient for stomatal control }\end{array}$ & Highly convex curve & 3.0 & & & & \\
\hline $\begin{array}{l}\text { Soil water depletion threshold for } \\
\text { failure of pollination }\end{array}$ & $\begin{array}{l}\text { Fraction of TAW at which pollination } \\
\text { starts to fail }\end{array}$ & 0.85 & & & & \\
\hline Calibrated parameters & & Default* & & rated & & \\
\hline $\begin{array}{l}\text { Crop coefficient for transpiration at } \\
\mathrm{CC}=100 \%\end{array}$ & Basal crop coefficient $\left(\mathrm{K}_{\mathrm{c}, \operatorname{Tr} \mathrm{x}}\right)$ & 1.10 & 1. & & & \\
\hline $\mathrm{BWP}^{*}$ & $\begin{array}{l}\text { Biomass (water) productivity adjusted } \\
\text { for } \mathrm{ET}_{\mathrm{O}} \text { and } \mathrm{CO}_{2}\left(\mathrm{~g} \mathrm{~m}^{-2}\right)\end{array}$ & 15 & 17 & & & \\
\hline $\mathrm{HI}_{\mathrm{o}}$ & Reference harvest index $(\%)$ & 0.40 & 0.3 & & & \\
\hline Canopy cover curve parameters & & Default* & 2008 & 2009 & 2010 & 2011 \\
\hline Maximum green canopy cover, $\mathrm{CC}_{\mathrm{x}}$, & $\%$ & 99 & 98 & 98 & 98 & 98 \\
\hline Canopy growth coefficient, CGC & $\% \mathrm{GDD}^{-1}$ & 0.45 & 0.71 & 0.62 & 0.72 & 0.74 \\
\hline Canopy decline coefficient, CDC & $\% \mathrm{GDD}^{-1}$ & 1.50 & 1.04 & 0.870 & 1.04 & 1.50 \\
\hline
\end{tabular}

* default parameters are tabled by Raes et al. (2012)

Note: GDD represents growing degree days; Conservative parameters are those that are expected to change little with time, with management condition or with the location 
Table 5. "Goodness-of-fit" indicators relative to the canopy cover curve using default and calibrated parameters

\begin{tabular}{llllllll}
\hline & $\begin{array}{l}\text { Year and } \\
\text { treatment }\end{array}$ & $\begin{array}{l}\text { Number of } \\
\text { observations }\end{array}$ & $\mathrm{b}$ & $\mathrm{R}^{2}$ & $\begin{array}{l}\text { RMSE } \\
(\%)\end{array}$ & $\begin{array}{l}\text { ARE } \\
(\%)\end{array}$ & EF \\
\hline Using & $2008, \mathrm{~T} 1$ & 13 & 0.81 & 0.93 & 20.0 & 31.5 & 0.49 \\
default & $2008, \mathrm{~T} 2$ & 13 & 0.80 & 0.93 & 20.3 & 31.8 & 0.48 \\
parameters & 2009 & 14 & 0.85 & 0.92 & 18.4 & 26.7 & 0.38 \\
& $2010, \mathrm{~T} 1$ & 12 & 0.76 & 0.81 & 25.2 & 36.1 & 0.23 \\
& $2010, \mathrm{~T} 2$ & 11 & 0.86 & 0.91 & 16.4 & 26.7 & 0.72 \\
& 2011 & 11 & 0.73 & 0.74 & 30.1 & 37.6 & -0.71 \\
\hline Using & $2008, \mathrm{~T} 1$ & 13 & 1.01 & 0.94 & 7.4 & 10.2 & 0.93 \\
calibrated & $2008, \mathrm{~T} 2$ & 13 & 1.01 & 0.94 & 7.2 & 9.9 & 0.94 \\
& 2009 & 14 & 0.97 & 0.95 & 5.7 & 9.0 & 0.94 \\
& $2010, \mathrm{~T} 1$ & 12 & 0.96 & 0.99 & 5.3 & 9.4 & 0.97 \\
& $2010, \mathrm{~T} 2$ & 11 & 1.04 & 0.99 & 4.3 & 7.2 & 0.99 \\
& 2011 & 11 & 1.00 & 0.99 & 5.4 & 7.9 & 0.95 \\
\hline
\end{tabular}

Table 6. "Goodness-of-fit" indicators relative to simulations of ASW (mm) with AquaCrop when using default and calibrated parameters and to SIMDuaKc model (Wei et al., 2015)

\begin{tabular}{lllllllll}
\hline & & $\begin{array}{l}\text { Year and } \\
\text { treatment }\end{array}$ & $\begin{array}{l}\text { Number of } \\
\text { pairs }\end{array}$ & $\mathrm{b}$ & $\mathrm{R}^{2}$ & $\begin{array}{l}\text { RMSE } \\
(\mathrm{mm})\end{array}$ & $\begin{array}{l}\text { ARE } \\
(\%)\end{array}$ & EF \\
\hline AquaCrop & Using default & $2008, \mathrm{~T} 1$ & 18 & 1.10 & 0.69 & 20.4 & 12.0 & 0.28 \\
& parameters & $2008, \mathrm{~T} 2$ & 18 & 1.16 & 0.35 & 26.8 & 17.5 & -1.11 \\
& 2009 & 21 & 0.99 & 0.83 & 11.4 & 5.9 & 0.79 \\
& $2010, \mathrm{~T} 1$ & 33 & 0.99 & 0.92 & 6.4 & 3.7 & 0.90 \\
& $2010, \mathrm{~T} 2$ & 33 & 1.06 & 0.81 & 11.6 & 7.0 & 0.56 \\
& 2011 & 32 & 1.06 & 0.70 & 19.9 & 10.2 & -0.12 \\
\hline & Using & $2008, \mathrm{~T} 1$ & 18 & 1.01 & 0.85 & 11.4 & 6.0 & 0.78 \\
& calibrated & $2008, \mathrm{~T} 2$ & 18 & 0.99 & 0.85 & 10.6 & 6.8 & 0.67 \\
& parameters & 2009 & 21 & 0.98 & 0.86 & 10.7 & 6.1 & 0.82 \\
& $2010, \mathrm{~T} 1$ & 33 & 0.94 & 0.82 & 12.3 & 6.5 & 0.64 \\
SIMDualKc & $2010, \mathrm{~T} 2$ & 33 & 0.95 & 0.22 & 15.6 & 10.0 & 0.19 \\
(Wei et al., 2015) & 2011 & 32 & 1.01 & 0.58 & 22.9 & 14.1 & -0.47 \\
\hline & $2008, \mathrm{~T} 1$ & 18 & 0.99 & 0.93 & 10.7 & 6.0 & 0.80 \\
& $2008, \mathrm{~T} 2$ & 18 & 0.98 & 0.84 & 12.5 & 8.4 & 0.54 \\
& 2009 & 21 & 0.97 & 0.95 & 7.8 & 3.5 & 0.90 \\
& $2010, \mathrm{~T} 1$ & 33 & 1.00 & 0.84 & 9.2 & 5.5 & 0.79 \\
& $2010, \mathrm{~T} 2$ & 33 & 1.02 & 0.83 & 8.6 & 5.1 & 0.76 \\
& 2011 & 32 & 1.03 & 0.86 & 9.3 & 4.8 & 0.76 \\
\hline
\end{tabular}


Table 7. Indicators of "goodness-of-fit" relative to simulating soil evaporation with AquaCrop and SIMDualKc models.

\begin{tabular}{cllllllll}
\hline & & $\begin{array}{l}\text { Year and } \\
\text { treatment }\end{array}$ & $\begin{array}{l}\text { Number of } \\
\text { observations }\end{array}$ & & $\mathrm{R}^{2}$ & $\begin{array}{l}\text { RMSE } \\
\left(\mathrm{mm} \mathrm{d}^{-1}\right)\end{array}$ & ARE (\%) & EF \\
\hline AquaCrop & Using default & $2008, \mathrm{~T} 1$ & 65 & 0.96 & 0.72 & 0.66 & 59.7 & 0.61 \\
& parameters & $2008, \mathrm{~T} 2$ & 54 & 1.08 & 0.84 & 0.48 & 68.2 & 0.72 \\
& 2009 & 82 & 1.04 & 0.72 & 0.76 & 78.8 & 0.65 \\
& $2010, \mathrm{~T} 1$ & 47 & 1.16 & 0.71 & 0.55 & 57.1 & 0.18 \\
& 2011 & 42 & 1.42 & 0.77 & 0.69 & 68.2 & -0.17 \\
\hline & $2008, \mathrm{~T} 1$ & 65 & 0.88 & 0.73 & 0.68 & 71.9 & 0.59 \\
& Using & $2008, \mathrm{~T} 2$ & 54 & 0.98 & 0.81 & 0.52 & 72.7 & 0.68 \\
& calibrated & 2009 & 82 & 0.89 & 0.76 & 0.66 & 56.0 & 0.74 \\
& & $2010, \mathrm{~T} 1$ & 47 & 0.84 & 0.65 & 0.50 & 66.3 & 0.31 \\
parameters & 2011 & 42 & 0.66 & 0.73 & 0.45 & 80.4 & 0.50 \\
\hline SIMDualKc & $2008, \mathrm{~T} 1$ & 65 & 0.97 & 0.85 & 0.52 & 57.7 & 0.76 \\
& $2008, \mathrm{~T} 2$ & 54 & 0.99 & 0.89 & 0.48 & 60.1 & 0.73 \\
& 2009 & 82 & 0.96 & 0.79 & 0.65 & 56.4 & 0.74 \\
& $2010, \mathrm{~T} 1$ & 47 & 0.90 & 0.86 & 0.38 & 60.5 & 0.62 \\
& 2011 & 42 & 0.95 & 0.84 & 0.24 & 39.5 & 0.85 \\
\hline
\end{tabular}

Table 8. Soil evaporation and evaporation ratio $\left(\mathrm{E}_{\mathrm{s}} / \mathrm{ET}_{\mathrm{c} \text { act }}\right)$ simulated when using AquaCrop (Aqua) and SIMDualKc (SIM) models after calibration, for each development stage and for the entire season

\begin{tabular}{|c|c|c|c|c|c|c|c|c|c|c|c|}
\hline \multirow{3}{*}{$\begin{array}{l}\text { Year/treat } \\
\text { ment }\end{array}$} & & \multicolumn{10}{|c|}{ Crop stage } \\
\hline & & \multicolumn{2}{|c|}{ Initial } & \multicolumn{2}{|c|}{$\begin{array}{l}\text { Crop } \\
\text { development }\end{array}$} & \multicolumn{2}{|c|}{ Mid-season } & \multicolumn{2}{|c|}{ Late season } & \multicolumn{2}{|c|}{ Entire season } \\
\hline & & Aqua & SIM* & Aqua & SIM* & Aqua & SIM* & Aqua & SIM* & Aqua & SIM* \\
\hline \multirow[t]{2}{*}{$2008, \mathrm{~T} 1$} & $\mathrm{E}_{\mathrm{s}}(\mathrm{mm})$ & 62 & 66 & 33 & 36 & 1 & 7 & 5 & 6 & 101 & 115 \\
\hline & $\mathrm{E}_{\mathrm{S}} / \mathrm{ET}_{\mathrm{c} \text { act }}(\%)$ & 97 & 85 & 36 & 40 & 1 & 6 & 15 & 19 & 31 & 36 \\
\hline \multirow[t]{2}{*}{ 2008, T2 } & $\mathrm{E}_{\mathrm{s}}(\mathrm{mm})$ & 61 & 57 & 31 & 30 & 1 & 7 & 5 & 7 & 98 & 101 \\
\hline & $\mathrm{E}_{\mathrm{s}} / \mathrm{ET}_{\mathrm{c} \text { act }}(\%)$ & 97 & 83 & 35 & 34 & 1 & 5 & 14 & 20 & 30 & 32 \\
\hline \multirow[t]{2}{*}{2009} & $\mathrm{E}_{\mathrm{s}}(\mathrm{mm})$ & 72 & 73 & 33 & 38 & 7 & 10 & 6 & 1 & 118 & 122 \\
\hline & $\mathrm{E}_{\mathrm{s}} / \mathrm{ET}_{\mathrm{c} \text { act }}(\%)$ & 91 & 80 & 37 & 43 & 5 & 7 & 14 & 4 & 33 & 35 \\
\hline \multirow[t]{2}{*}{ 2010, T1 } & $\mathrm{E}_{\mathrm{s}}(\mathrm{mm})$ & 45 & 44 & 30 & 32 & 2 & 2 & 3 & 7 & 80 & 85 \\
\hline & $\mathrm{E}_{\mathrm{s}} / \mathrm{ET}_{\mathrm{c} \text { act }}(\%)$ & 92 & 72 & 24 & 28 & 3 & 3 & 9 & 24 & 27 & 30 \\
\hline \multirow[t]{2}{*}{$2010, \mathrm{~T} 2$} & $\mathrm{E}_{\mathrm{s}}(\mathrm{mm})$ & 46 & 46 & 14 & 23 & 1 & 3 & 3 & 7 & 64 & 79 \\
\hline & $\mathrm{E}_{\mathrm{s}} / \mathrm{ET}_{\mathrm{c} \text { act }}(\%)$ & 91 & 72 & 12 & 22 & 1 & 4 & 9 & 24 & 21 & 28 \\
\hline \multirow[t]{2}{*}{2011} & $\mathrm{E}_{\mathrm{s}}(\mathrm{mm})$ & 47 & 43 & 51 & 52 & 1 & 9 & 2 & 2 & 101 & 106 \\
\hline & $\mathrm{E}_{\mathrm{s}} / \mathrm{ET}_{\mathrm{c} \text { act }}(\%)$ & 97 & 80 & 40 & 43 & 1 & 7 & 5 & 7 & 29 & 32 \\
\hline
\end{tabular}

*Adapted from Wei et al. (2015) 
Table 9. Deviations between predicted and observed soybean final biomass and yield $\left(\mathrm{kg} \mathrm{ha}^{-1}\right)$, when using default and calibrated parameters, compared with Stewart's and SIMDualKc combination

\begin{tabular}{|c|c|c|c|c|c|c|c|c|c|c|c|}
\hline & \multirow{3}{*}{ Year } & \multirow{3}{*}{$\begin{array}{l}\text { Observed* } \\
\left(\mathrm{kg} \mathrm{ha}^{-1}\right)\end{array}$} & \multicolumn{6}{|c|}{ AquaCrop } & \multirow{2}{*}{\multicolumn{3}{|c|}{$\begin{array}{l}\text { Stewart's model with T data } \\
\text { from SIMDualKc }\end{array}$}} \\
\hline & & & \multicolumn{3}{|c|}{ Default parameters } & \multicolumn{3}{|l|}{ Calibrated } & & & \\
\hline & & & $\begin{array}{r}\text { Predic } \\
(\mathrm{kg} \mathrm{h} \\
\end{array}$ & $\begin{array}{r}\text { dDeviat } \\
)(\mathrm{kg} \mathrm{h} \\
\end{array}$ & & $\begin{array}{l}\text { Predicted } \\
\%\left(\mathrm{~kg} \mathrm{ha}^{-1}\right)\end{array}$ & $\begin{array}{l}\text { Deviation } \\
\left(\mathrm{kg} \mathrm{ha}^{-1}\right)\end{array}$ & & $\begin{array}{l}\text { Predicted } \\
\left(\mathrm{kg} \mathrm{ha}^{-1}\right)\end{array}$ & $\begin{array}{l}\text { Deviation } \\
\left(\mathrm{kg} \mathrm{ha}^{-1}\right)\end{array}$ & $\%$ \\
\hline \multirow{6}{*}{$\begin{array}{l}\text { Dry final above } \\
\text { ground biomass, } \\
\text { B }\end{array}$} & 2008-T1 & $9631( \pm 690)$ & 6532 & -3099 & 32.2 & 9742 & 111 & 1.2 & & & \\
\hline & 2008-T2 & $8948( \pm 906)$ & 6509 & -2439 & 27.3 & 9722 & 774 & 8.6 & & & \\
\hline & 2009 & $9118( \pm 651)$ & 6387 & -2731 & 30.0 & 9425 & 307 & 3.4 & & & \\
\hline & 2010-T1 & $11840( \pm 617)$ & 6530 & -5310 & 44.8 & 9731 & -2109 & 17.8 & & & \\
\hline & 2010-T2 & $10965( \pm 598)$ & 6949 & -4016 & 36.6 & 10143 & -822 & 7.5 & & & \\
\hline & 2011 & $10757( \pm 510)$ & 6536 & -4221 & 39.2 & 9830 & -927 & 8.6 & & & \\
\hline \multirow[t]{6}{*}{ Dry final yield, Y } & 2008-T1 & $3778( \pm 272)$ & 2613 & -1165 & 30.8 & 3703 & -75 & 2.0 & 4046 & 267 & 7.1 \\
\hline & 2008-T2 & $3549( \pm 358)$ & 2607 & -942 & 26.5 & 3698 & 149 & 4.2 & 4009 & 461 & 13.0 \\
\hline & 2009 & $3454( \pm 246)$ & 2192 & -1262 & 36.5 & 3522 & 68 & 2.0 & 3689 & 234 & 6.8 \\
\hline & 2010-T1 & $4230( \pm 222)$ & 2556 & -1674 & 39.6 & 3731 & -499 & 11.8 & 4443 & 214 & 5.1 \\
\hline & 2010-T2 & $3578( \pm 196)$ & 2819 & -759 & 21.2 & 3884 & 306 & 8.6 & 4260 & 682 & 19.1 \\
\hline & 2011 & $3222( \pm 151)$ & 2550 & -672 & 20.9 & 3637 & 415 & 12.9 & 3374 & 152 & 4.7 \\
\hline
\end{tabular}

$*$ dried at $65 \pm 5^{\circ} \mathrm{C}$; Standard deviation between brackets 

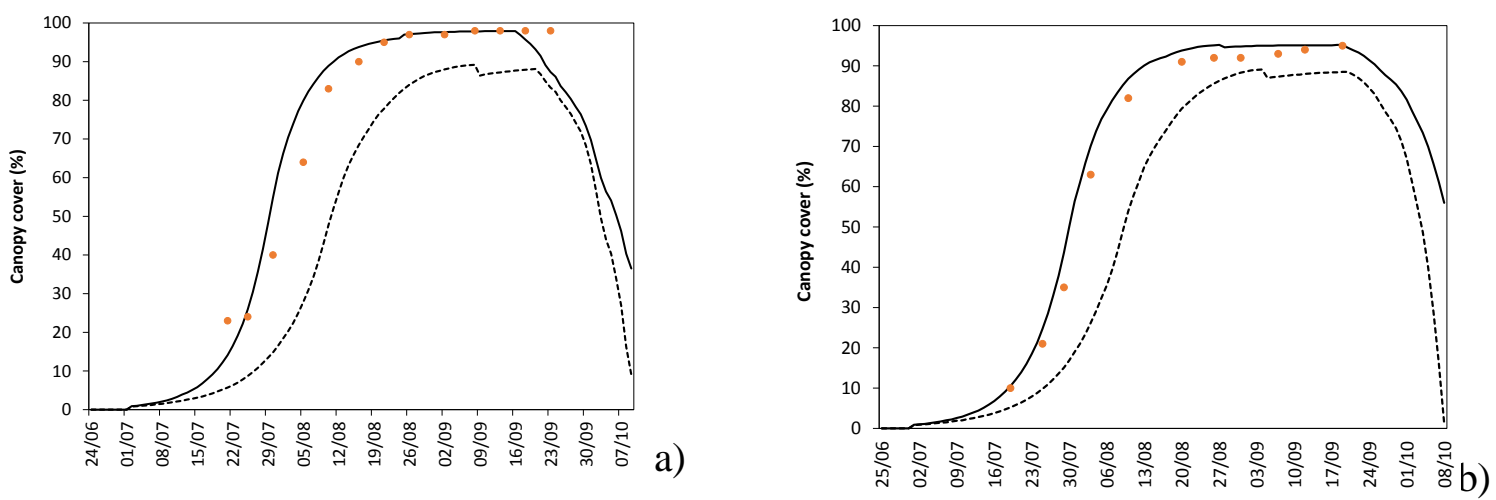

Fig. 1. Best and worse simulated canopy cover (CC) curves when using default parameters (---) and after calibration (—) compared with observed values ( ${ }^{\circ}$ ): (a) T1 in 2008, and (b) T2 in 2010. 

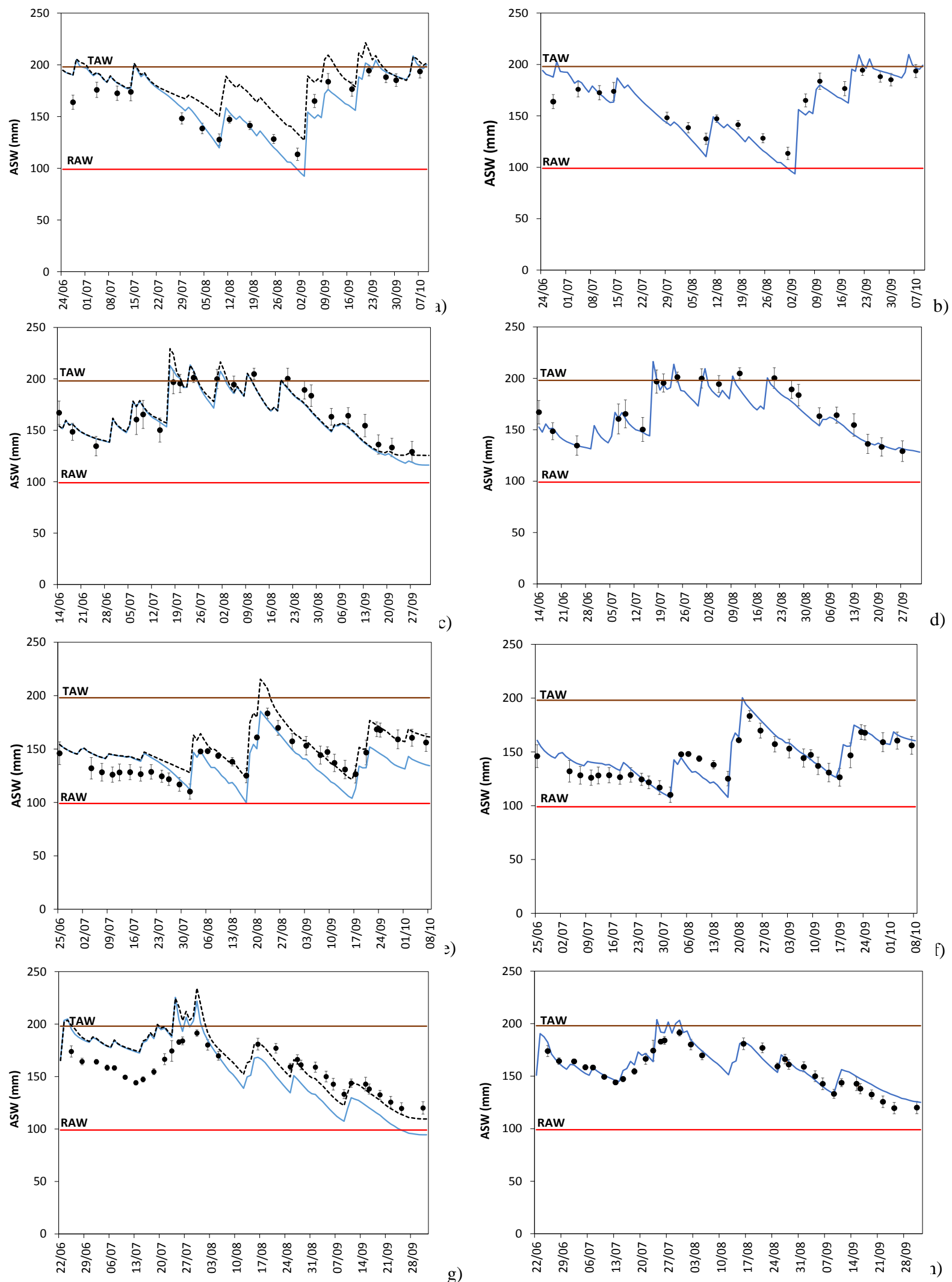

Fig. 2. Observed (•) and simulated (-) daily available soil water (ASW) with AquaCrop, on the left, compared with SIMDualKc, on the right (data from Wei et al., 2015): (a, b) T1 in 2008, calibration; (c, d) 2009 , (e, f) T2 in 2010, and (g, h) 2011 (error bars refer to the standard deviation of ASW observations). Also included the simulation with AquaCrop when using default parameters (---) 

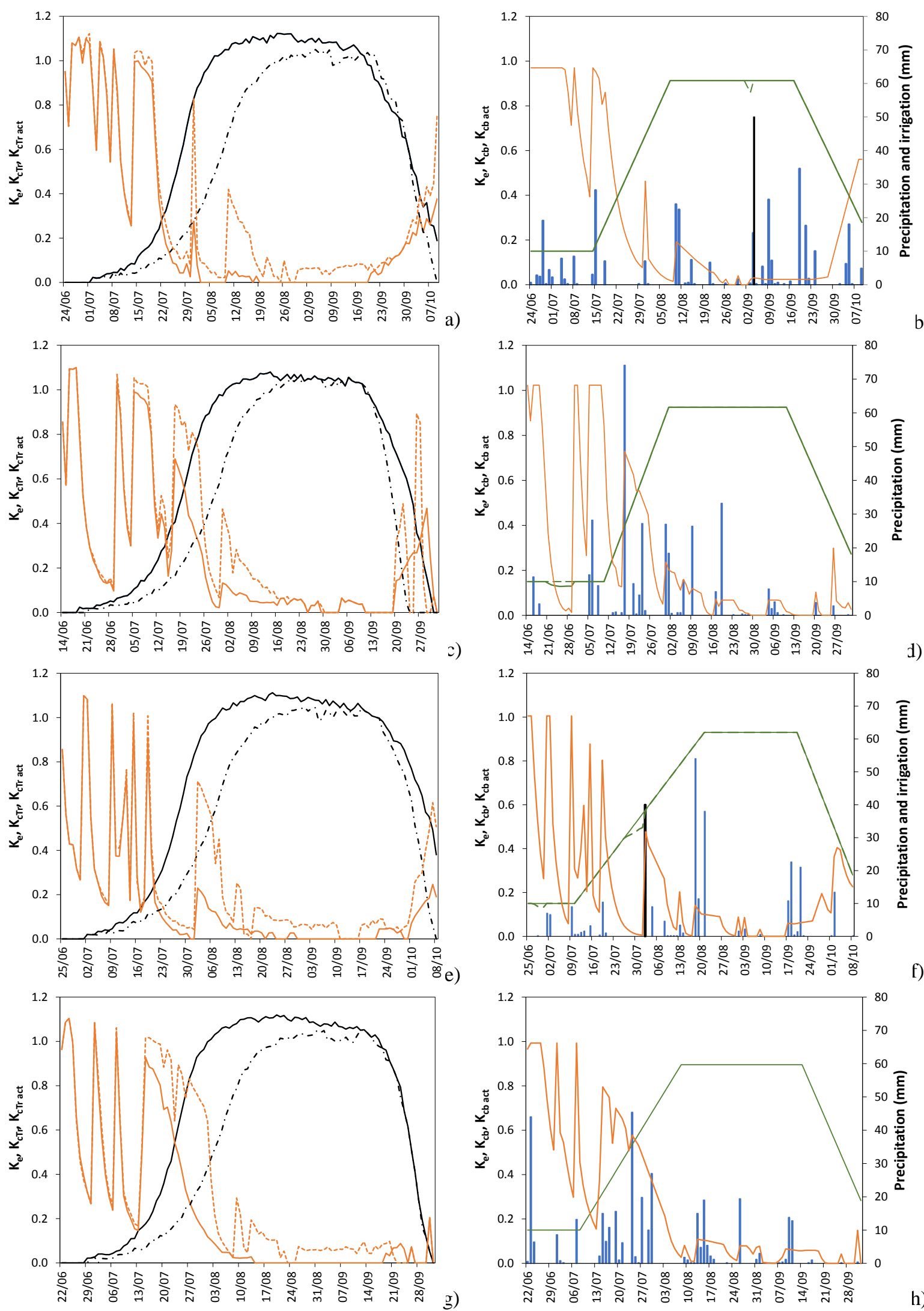

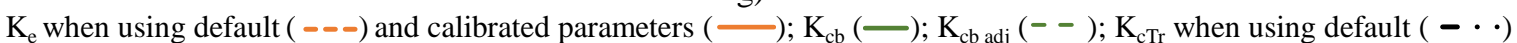

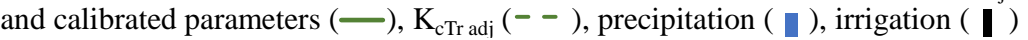

Fig. 3. Seasonal variation of the soil evaporation coefficient $\left(\mathrm{K}_{\mathrm{e}}\right)$ and crop coefficients $\left(\mathrm{K}_{\mathrm{cb}}\right.$ or $\left.\mathrm{K}_{\mathrm{c}, \mathrm{Tr}}\right)$ relative to: (a, b) T1 in 2008, calibration; (c, d) 2009, (e, f) T2 in 2010, and (g, h) 2011. For simpler visualization, rainfall and irrigation are represented only in the pictures on the right. 

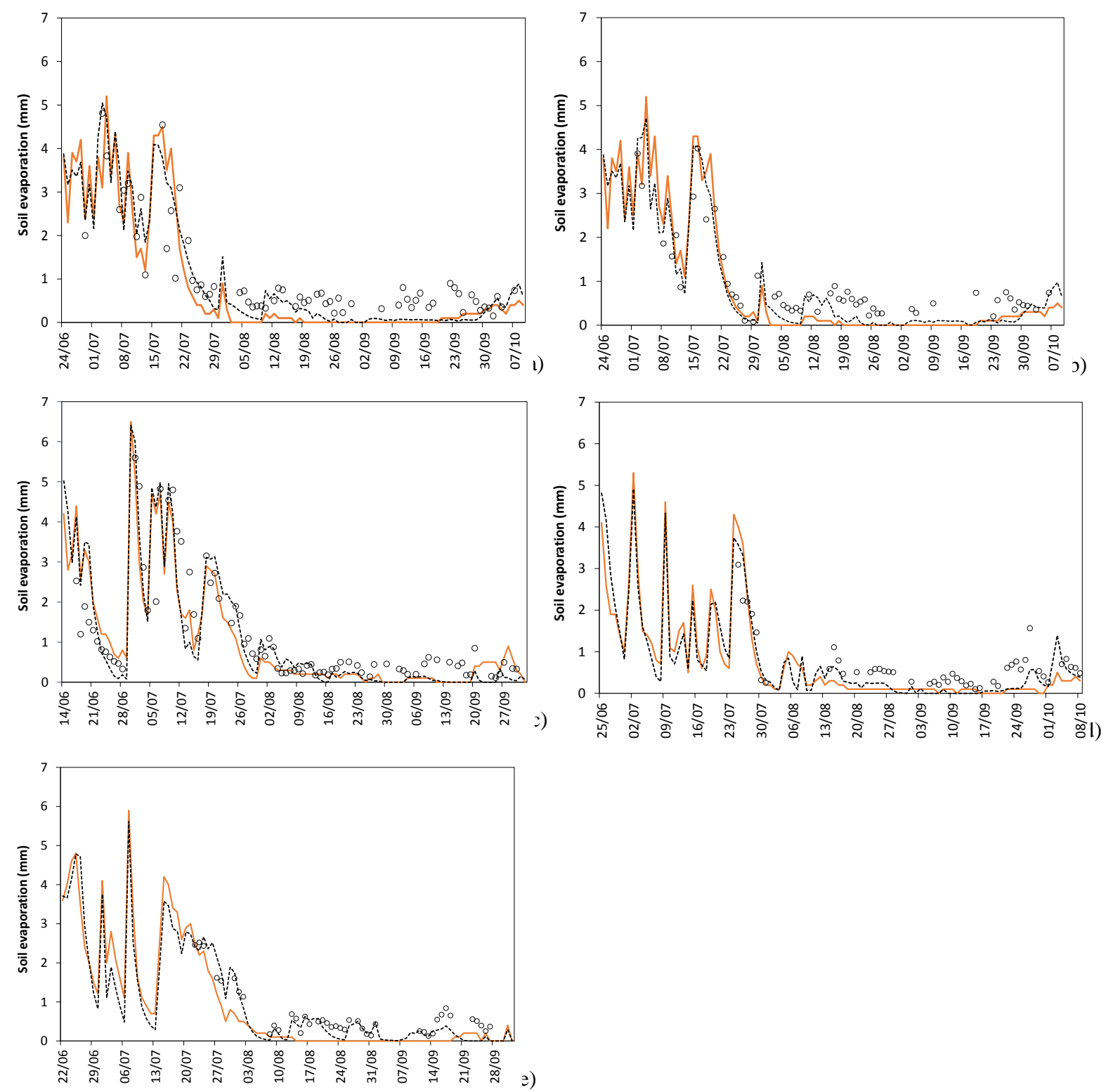

Fig. 4. Daily soil evaporation $\left(E_{s}\right)$ dynamics along soybeans seasons when using the AquaCrop after adequate calibration ( - ) and SIMDualKc (..--.) compared with microlysimeters observations ( $(0)$ for: (a) T1 in 2008, calibration, (b) T2 in 2008; (c) 2009, (d) T1 in 2010, and (e) 2011 (SIMDualKc data from Wei et al., 2015) 